NBER WORKING PAPER SERIES

\title{
EFFECTS OF AIR QUALITY REGULATION ON DECISIONS OF FIRMS IN POLLUTING INDUSTRIES
}

\author{
Randy Becker \\ Vernon Henderson
}

Working Paper 6160

http://www.nber.org/papers/w6160

\author{
NATIONAL BUREAU OF ECONOMIC RESEARCH \\ 1050 Massachusetts Avenue \\ Cambridge, MA 02138 \\ September 1997
}

\begin{abstract}
Support of the NSF (grant SBR9422440 to the National Bureau of Economic Research) is gratefully acknowledged, as well as the Alfred P. Sloan Foundation to the NBER project on Industrial Technology and Productivity. This work was carried out at the Boston Research Data Center of the U.S. Bureau of the Census. We thank Arnie Reznek and Joyce Cooper for their help and cooperation. Tim Dunne also provided early advice on the use of the LRD. We are indebted to Leslie Papke and Jeff Wooldridge (1991) for use of their program to calculate robust standard errors in conditional Poisson models. The work has benefited from insightful comments by Arik Levinson, as well as Wayne Gray, Gib Metcalf, and participants in seminars at British Columbia, Brown, Harvard, Mannheim and RFF and presentations at the AEA, NTA, RSA, and Western Economic Association meetings. The opinions and conclusions expressed in this paper are those of the authors and do not necessarily represent those of the U.S. Bureau of the Census or the National Bureau of Economic Research. All papers are screened to ensure that they do not disclose confidential information. This paper is part of NBER's research programs in Productivity and Public Economics.

(C) 1997 by Randy Becker and Vernon Henderson. All rights reserved. Short sections of text, not to exceed two paragraphs, may be quoted without explicit permission provided that full credit, including $(\mathcal{O}$ notice, is given to the source.
\end{abstract}


Effects of Air Quality Regulation on

Decisions of Firms in Polluting Industries

Randy Becker and Vernon Henderson

NBER Working Paper No. 6160

September 1997

Productivity and Public Economics

\section{ABSTRACT}

This paper examines unintended effects of air quality regulation on decisions of major polluters, using plant data for 1963 to 1992 . A key regulatory tool since 1978 is the annual designation of county air quality attainment status, where non-attainment status triggers specific equipment requirements for new and existing plants. We find, in the later years of regulation, that, ceteris paribus, non-attainment status reduces expected births in polluting industries by $40-50 \%$, resulting in a shift of polluting activity to cleaner, less populated attainment areas. Starting in the 1970s effects appear first for industries with bigger plant sizes and then, within industries, first for corporate plants relative to the much smaller non-affiliate, or single plant firm sector. In all industries, non-affiliates face less regulation than the bigger corporate plants, resulting in a permanent shift away from corporate plant production in some industries. Older plants benefit from grandfathering provisions greatly enhancing survival probabilities. Finally, the negotiation and permitting process under regulation appears to induce much greater up-front investments by new plants, so that, in non-attainment areas, regulation induces $50-100 \%$ increases in initial plant sizes compared to attainment areas. But for plants over 10 years of age there are no size differences.

Randy Becker

Department of Economics

Brown University

Box B

Providence, RI 02912
Vernon Henderson

Department of Economics

Brown University

Box B

Providence, RI 02912 and NBER

j_henderson@brown.edu 
Effects of Air Quality Regulations on Decisions

of Firms in Polluting Industries

Randy Becker

Brown University and U.S. Bureau of Census

Vernon Henderson

Brown University and NBER

This paper investigates the effects of air quality regulation in the USA on firm decisions concerning plant locations, births and survivals, sizes, and investment patterns, in major polluting industries. The intent of the Clean Air Act and its Amendments from 1970 on is to induce/coerce plants to limit source emissions that lead to air pollution, so localities meet national air quality standards. In general, the national strategy is to have plants invest in "greener" production equipment and to devote resources to containing and limiting emissions from day-to-day operations. While regulation has generally been very successful in curbing many forms of emissions, it has had other unintended and potentially costly impacts on firm decisions, which we explore in this paper.

Unintended effects include relocation of polluting industries from more to less polluted areas, relative poliferation of small-scale enterprises in some industries altering industrial structure, and changes in investment patterns - the timing and phasing of investments and decisions as to whether and when to open new plants or close old ones. Some of these effects may not be socially bad. For example, relocation of polluting industries to less polluted areas generally means plants move to areas with lower populations and hence fewer pollution victims to damage. This paper does not quantify these welfare effects per se. Rather the 
purpose is to take the first step in that direction - to identify key effects of air quality regulation and their welfare considerations. That will help us understand the complexity of reactions to regulation, think about alternative regulatory policies, and suggest relevant issues for welfare analysis.

We focus on air quality regulation relevant to ground level, or tropospheric ozone $\left[\mathrm{O}_{3}\right]$ - a major component of "smog." Ozone, along with PM-10, is the current target of the US Environmental Protection Agency [EPA] air quality regulatory activity, because it has proved to be the most persistent air pollution problem. From a research point of view, ozone presents an ideal case because of the considerable variation over time, space, and industrial sectors in air quality regulation, allowing us to better assess the effects of stronger versus weaker regulatory activity. The EPA recently announced that is proposing even more stringent standards for ozone (New York Times, 11/28/96), which makes the issue of the effects of ozone regulations even more pressing.

Ozone forms in a complex fashion, based on emissions of mostly volatile organic compounds [VOC] and nitrogen oxides $\left[\mathrm{NO}_{x}\right]$ from various sources and on atmospheric conditions such as wind, temperature, and sunlight. Regulation focuses on mobile and stationary industrial sources of VOC and, to some extent, $\mathrm{NO}_{x}$ emissions. This paper will examine the effects of regulation on manufacturing industries who are major VOC (and $\mathrm{NO}_{x}$ ) emitters, but not major polluters in other air quality dimensions (so as to not confound findings with regulation of other criterion pollutants). As discussed and identified later, these industries are industrial organic chemicals, miscellaneous plastics, metal containers and wood furniture. We will also comment on commercial printing and automobiles.

To analyze regulatory effects, we first discuss the regulatory process as it has evolved (see EPA (1971, 1972, 1973, 1978a, 1978b, 1992a, 1992b, and 1995), Laws (1992), Liroff (1986), Melnick (1983), and Waxman (1992)). Then we examine the literature on prior research. That discussion will lead to formulation of hypotheses. Then after discussing the data and choice of industries, we turn to the sections of the paper studying the evaluation of 
firm choices governing plant births and closures, sizes, and investment patterns, as affected by regulation.

\section{Formulating Regulatory Hypotheses}

\section{The Regulatory Process}

Prior to 1970 , air quality regulation was mostly left up to the states. Disappointed by the states' progress Congress enacted the 1970 amendments to the Clean Air Act which dramatically increased the role of the federal government (and the newly created EPA) in air quality regulation. A key provision was the establishment of national ambient air quality standards [NAAQS's] for all areas of the country. The standard for ozone is based on an area's annual second highest daily maximum hourly concentration. If this particular reading exceeds 0.12 parts per million ( $0.08 \mathrm{ppm}$ prior to 1979), the area is defined to be in nonattainment of the NAAQS for ozone. Otherwise, it is said to be in attainment. The 1970 amendments mandated that each state develop and submit a State Implementation Plan [SIP] detailing exactly how it intended to bring its non-attainment areas into attainment. SIP's were to be submitted by 1972 , and attainment of national standards in all air pollutants was to be achieved by the mid-1970s. Two decades later, many areas remain in violation of those standards.

The years immediately following the 1970 amendments were ones of confusion. States lacked the technical expertise and resources to implement effectively a regulatory system in a short period of time, including good information on what emission reductions were needed to achieve attainment. An (escape) clause in the regulations stated that strict controls need not be implemented if pending federal regulations on automobile emissions would be sufficient to bring an area into attainment. Based on crude estimates, some states did promulgate control technologies and emission limits for stationary sources, usually without compliance schedules. The EPA approved nearly all SIPs. Lawsuits were filed by industry groups stating SIPs were too stringent, and by environmental groups who thought they were too lax. The 
ensuing uncertainty paralyzed most efforts to carry out SIPs. The only plants typically facing any regulation were the very largest. These problems led to the 1977 amendments to the Clean Air Act.

Under the 1977 amendments each July (beginning in 1978), each county in the United States is officially classified being either in or out of attainment of the national standards for each of the criteria pollutants. ${ }^{1}$ SIPs were to be revised and resubmitted by 1979 , detailing how states intended to bring violating counties into attainment by 1987. Federal enforcement was strengthened, with the potential to withhold federal grants on, for example, highway funds to recalcitrant states or to impose a moratorium on construction of all new plants. The EPA could impose civil penalties directly on polluters.

In terms of regulating plant emissions, as specified in SIPs, the key mechanism became technological controls on equipment. New polluting plants wanting to locate in nonattainment counties are subject to Lowest Achievable Emission Rate [LAER], requiring the installation of the cleanest technology in existence, regardless of its costs. In addition, these plants (which include existing plants considering expansion and modification) can be required to purchase pollution offsets from existing plants. Existing plants in non-attainment areas are subject to Reasonably Available Control Technology [RACT] - usually retro-fitting controls that do not place undue economic burdens on plants. These latter provisions are negotiated case-by-case, often with long (or indefinite) delays for small sources.

Attainment areas are subject to Prevention of Significant Deterioration [PSD], in terms of future degradation of air quality. New and modified sources in such areas with the potential to emit more than, originally, 100 tons of any criteria pollutant per year are supposed to install Best Available Control Technology [BACT], negotiated case-by-case, with a sensitivity to economic burden unlike the LAER requirements in non-attainment areas. Existing and new small plants in attainment areas are not subject to any technological standards.

\footnotetext{
${ }^{1}$ These designations are published each year in the Code of Federal Regulations (Title 40, Part 81, Subsection C).
} 
Note there are several key aspects to technological controls. First, new plants and existing plants are each subject to much stricter controls in non-attainment areas, relative to attainment areas. This aspect favors development of new plants in attainment, relative to non-attainment areas. Second, new small plants in attainment areas as well as existing plants are subject to no regulations. Overall, this favors development of small-scale enterprises at the expense of bigger plants. It may even encourage downsizing of existing large plants. Third, existing equipment at the time of regulation was grandfathered, subject to either no regulation or at most retrofitting. This confers a relative cost advantage on older plants, potentially increasing their length of life.

How are regulations enforced? Apart from reviewing the literature, we interviewed officials and reviewed documents and files of the Air Quality Division of the R.I. Department of Environmental Management [DEM] and we interviewed plant managers and environment engineers at a few important VOC emitting plants in Rhode Island. Rhode Island is a non-attainment area, which has been viewed by the EPA as a fairly cooperative state. In enforcing regulations, states have limited resources. Given that, as well as an EPA focus on "class A" polluters (in 1977, those emitting over 100 tons per year of any criterion pollutant), states tend to concentrate their regulatory resources on big plants. This strategy has implications. First, in the early years, only bigger plants were regulated. Small and some medium-size plants were effectively exempted. Not only did regulators not have the resources to regulate these plants, but they typically did not know either of the existence of certain plants or that such plants were VOC or $\mathrm{NO}_{x}$ emitters. So, even in non-attainment areas, we expect to see a very different reaction to regulation by bigger versus smaller plants in the early years of regulation. With time the local DEM worked its way through the list of bigger plants and moved onto medium- and smaller-size plants. Nonetheless, annual inspections and enforcement today remain focused on big plants, with smaller plants either never inspected or inspected only once or twice a decade. Again, this confers a cost advantage on smaller plants. To confirm these impressions based on RI interviews, we examined data 
on inspections listed by the EPA. These are discussed later in the paper in Table 1, but they indicate a strong positive relationship between size and likelihood of being inspected in the late 1980's and early 1990's.

Our interviews were also instructive about how the regulatory process affects behavior of plants in equipment choices. In choosing new equipment or with major retrofitting, there are issues concerning the interpretation of LAER, RACT, and BACT. Firms engage in a costly negotiation process with officials of the local DEM and sometimes regional EPA, using their own engineers and also making extensive use of consultants. Such negotiations for a major plant can involve almost weekly meetings over, say, a two-year period, with all the required background work. Later, we will argue that, in setting up new plants or engaging in expansion of existing plants, relative to phased-in investments of the past, now large plants do investments in bigger lumps (i.e., "all at once," relatively speaking) to avoid repeated negotiations and to ensure consistency of equipment specifications across what would have been different investment phases in the past.

\section{Previous Literature}

The main issue that has been explicitly addressed by the literature is that of plant location. While it seems likely polluting plants would avoid heavily-regulated areas, previous studies have generally concluded that environmental regulation does not affect plant location decisions (see Levinson (1994) and Gray (1996) for a review). Many studies have been at the state-level, thus overlooking the often significant regulatory differences within a state. Some studies have lumped together disparate industries in their analyses - such as those that look at "all manufacturing" or two-digit SIC categories of manufacturing. We will argue that regulations only affect major polluters, as identified at the three-digit or four-digit level. Given the wide array of industries used in such studies, the proxies for environmental regulation are not industry specific. They are based on Congressional voting records, the existence of environmental laws, ratings of air and water quality, measures of overall spending 
on abatement programs, employment in state regulatory agencies, and so on.

Additionally, some studies (e.g., Bartik (1988)) focus on just the early confused period of regulation before 1978. Others (e.g., McConnell and Schwab (1990)) either or both look at an industry with too small a sample size to make inferences (i.e., automobiles with just 50 new plants over ten years) or use cross-sectional data or estimation methods. The latter is critical. In looking for whether plants locate away from non-attainment areas, we must recognize that counties are in non-attainment because plants (polluting and otherwise) have historically viewed them as favorable places to locate. If these "favorable" attributes are not controlled for (say, by fixed effects methods), then, in cross-sectional analysis, a nonattainment variable will pick up these effects and its coefficient will be biased.

Two recent studies that have used county non-attainment status for air quality dimensions relevant to specific industries as a proxy for stringent environmental regulation have found some compelling results. Kahn (1994) finds that growth in manufacturing employment has been slower in particulate non-attainment counties. Henderson (1996) uses County Business Patterns data to look at the effects of county ozone non-attainment on the stock of plants in VOC-emitting industries. He finds a significant reduction in polluting plants in counties which switch into non-attainment status. However, he only looks at plant stocks within the regulatory period (1978-87) and has no information on the asymmetric impact of regulation on the birth and death processes.

This paper adds to and improves upon this existing literature in several ways. Besides location decisions of new plants, we look at survival decisions of existing plants. For both we distinguish among (1) different types of industries, (2) bigger and smaller plant sectors of industries, (3) pre (before 1972) and the regulatory time period, (4) earlier and later years in the regulatory period, and (5) the likely severity of regulations in different non-attainment areas. Besides births and deaths, we look at plant decisions concerning size and investment patterns. Finally, we use detajled plant and firm level Census data over a thirty-year period. 
Hypothesized Impacts of Regulation.

The impacts of regulations that we study in this paper are in reality a blend of preliminary hypotheses, regulatory phenomena that were revealed in the course of plant interviews, presentation of preliminary results, and discussions with other researchers, and patterns that appeared to be present in preliminary examinations of the data. This blend has become a set of refined hypotheses we now discuss. In deciding whether and when to put a plant into operation or take it out of operation in a county, a firm is acting to maximize net expected present value. On the spatial side, considerations are straightforward. Equipment costs of locating any new plant in non-attainment areas rose significantly (due to LAER), while in attainment areas for small plants they remained the same and for big plants rose more modestly. Thus it became less profitable to start up new polluting plants in non-attainment areas, and there should be a significant increase in the relative number of births in attainment areas. The magnitude of this shift will depend on the likely severity of regulation in different non-attainment areas.

A shift to attainment areas has welfare implications. First, on the production side it is costly, causing plants to choose traditionally less profitable birth sites, to avoid air quality regulation in more profitable traditional sites in non-attainment areas. Second, it improves air quality in non-attainment areas and hurts it in attainment areas. Such a spreading out of pollution may actually be good, dampening ozone peaks in low air quality regions. However, it is against the intention of the Clean Air Act.

The timing of the shift of activity to attainment areas will vary within and across industries. We will divide each industry into two sectors: the "corporate" sector where plants are owned by multi-plant firms and the "non-affiliate" sector where firms are single plant-firms. Corporate plants are much larger, typically tenfold controlling for age; and serve large regional or even international markets with relatively standardized products. The smaller non-affiliates tend to serve more local markets with special-order products. Across industries, average plant sizes also differ enormously by production process. Since regulators 
focused on the biggest plants first and then successively incorporated smaller plants in nonattainment areas, we expect the relative shift to attainment areas to occur first for corporate plants and then later for non-affiliates. Similarly across industries, we expect the shift to occur in bigger plant industries first.

Apart from locational considerations, in examining effects within industries, there are a number of other critical distinctions. We focus on two. First new plants compared to "grandfathered" older plants are subject to greater regulation. Starting with the latter, existing plants with grandfathered equipment operate, at least for a short period of time, with a cost advantage relative to new plants who are required to purchase more expensive regulated equipment (relative to past equipment). We would expect firms to prolong the life of existing grandfathered plants and delay openings of costly new plants or delay renewals of existing plants. Grandfathering effects could, for example, extend the lives of plants born prior to the early 1970's, with the onset of regulation in the mid to later 1970's. It could extend also the lives of plants born in the early years of regulation, as regulations for successive waves of new potential plants tighten over time. Grandfathering effects may be strongest in non-attainment areas where all new plants are subject to regulation. In terms of welfare implications, grandfathering obviously slows down the "natural turnover" process of plants, keeping otherwise less profitable plants in business and retarding the entry of new enterprises, in a Jovanovic (1982) context.

In terms of the second distinction, we expect the accumulative effects of regulation to differ between bigger and smaller plants. Smaller plants in attainment areas escape regulation all together and those in non-attainment areas come under regulation later and probably in a weaker form. In our data, all this confers a competitive advantage on the non-affiliate sector, compared to the corporate sector, potentially allowing the market share of nonaffiliates to expand. This hypothesis has the most relevance in industries in which corporate plants are traditionally large (qualifying as class A polluters) relative to non-affiliates. This potential shift in industrial structure towards smaller non-affiliate plants also has welfare 
implications, if either long-run average costs vary significantly by plant and/or firm size or product composition and variety differs between non-affiliates and the corporate sector. For the latter there may be consumer losses in national markets for "brand name" products of the corporate sector and gains in local special order markets served by non-affiliates.

In viewing the potential change in industrial structure there are a number of subtleties. We note two in particular. First, from the early 1970's on, visible corporations with deep liability pockets operating very large plants know they are going to be heavily regulated in setting up operations anywhere. Following the literature on irreversible investments under uncertainty (Pindyck (1992), Dixit and Pindyck (1995)), corporate firms are subject to input cost uncertainty about future green equipment undergoing development, and future operating costs as state regulators get up to speed. It seems plausible that firms in industries with high irreversible capital investments could exercise the options either to delay starts or to delay expansions and renewal in existing plants until new information becomes available that determines the extent to which they still want to operate in this industry. That has several related consequences. First, overall per plant sales and level of operations may dip in the early years of regulation. Second, corporate births may drop, particularly in nonattainment areas in the early regulatory years. Second, if for a specific industry there is later "bad news," births may stay permanently low - large-scale operations withdraw from the market. Finally, grandfathering effects may be enhanced because maintaining older (failing or more obsolete), unregulated equipment becomes more attractive than immediate replacement with regulated new or renewed plants.

In contrast, consider the non-affiliates in industries in which there is a large plant corporate sector. Potential new non-affiliates may be subject to Pindyck's technical uncertainty (Pindyck (1992)). In the early years of regulation, if they locate in non-attainment areas, they don't know the extent to which they will escape regulation there; and, if they locate in unfamiliar unregulated attainment areas, they will be poorly informed about market conditions there. Only by entering can they learn the nature of conditions; and then exercise the 
option to exit early, if they get "bad news" concerning their competitive position in a location. Thus, relative births of non-affliated plants in industries with a large plant corporate sector may speed up in the early years of regulation. However, since the intention is experimentation with an exit option, we expect low survival rates for these small experimenters. There are costs associated with experimentation, in the sense that, in order to learn about the new regulatory regime, a number of new small plants invested in experimental operations. The issue concerns whether a different regulatory design would have mitigated such costs - one where all plants were regulated uniformly over space and size. We comment further on this possibility later.

Given the relevance of size in regulation, regulation may in turn affect the size and investment patterns of large corporate plants. First, we might expect downsizing - reduction in sizes of existing plants, and new plants growing to smaller sizes historically. Pure regulatory procedures whereby regulators target the largest plants create an incentive for individual plants to downsize. Downsizing also reduces the investment at risk at any site, in the face of variation in the application of regulations across and even within states. An alternative hypothesis could be that greener equipment involves larger capacity investments and larger scale of operations. In general, downsizing does not seem to be a general phenomenon of regulation, although increased capital per worker may be.

For investment patterns, as noted earlier, in later years given negotiation costs and considerations of consistency of equipment specifications, large plants are likely to have higher up-front investments and less phasing-in of investments, especially in non-attainment areas. So initial irreversible investments will increase in non-attainment areas, although over the long-term plant sizes may decline (i.e., not grow as large as historically or as in attainment areas). Larger up-front commitments are likely to also increase medium-term survival rates of new plants. Firms are undertaking investment projects where potential exit options are more costly and thus only undertake the project if survival is more likely. Again this limits the natural rate of turnover of plants in Jovanovic (1982) context. 
Industry Choice and Data.

To choose a set of industries, from the Sector Notebook Project series (EPA, 1995) we took the 13 industries that typically emit over 25,000 short tons of VOC's a year, many of which are also major $\mathrm{NO}_{x}$ emitters. From that group we then selected industries where VOC emissions exceeded those of each of $\mathrm{CO}, \mathrm{SO}_{2}, \mathrm{PM}-10$, and $\mathrm{PT}$, to isolate industries which are the focus of ozone regulation, as opposed to other criterion pollutants. These industries are organic chemicals, rubber and miscellaneous plants, fabricated metals, wood furniture and fixtures, commercial printing, and motor vehicles, bodies and parts. Of these we discarded the motor vehicles industry due to lack of activity - there are typically about 50 plant births in this industry every ten years (McConnell and Schwab (1990)), whereas our industries will have at least three times that number every five years.

For the remaining five industries, based on EPA (1978) and EPA (1992b), we picked three- or four-digit SIC categories, which seemed to be the key contributors to VOC's and the target of EPA attention. These are (1) industrial organic chemicals (specifically SIC 2865 and 2869 combined) an industry that actually manufactures VOC's (2) miscellaneous plastic products (SIC 308) which use VOC's intensively in production (3) metal cans and barrels (SIC 3411 and 3412 combined) a major "surface coater" using VOC's to deliver paint pigments to surfaces (4) wood furniture (SIC 2511) another major surface coater and (5) commercial printing, gravure (SIC 2754). The last industry is very small before 1970. Since we are focused on pre versus regulatory years comparisons, for commercial printing, we only footnote some key results (which are supportive of our other results).

In general, these four industries - industrial organic chemicals, plastics, metal containers and wood furniture - are quite different and have different experiences under regulation. The key differences are plant sizes, industry sizes, and role of the corporate sector. Some basic numbers are given in Table 1. The stock of plants and average employment numbers are for the end years (1972, 1982 and 1992). The births (since the prior Census) and their corresponding new investment numbers are for the same ending years. From Table 1, plastics 
INDUSTRIAL ORGANIC CHEMICALS

$\underline{1967-72}$

684

stock of plants

$\%$ corporate

new plants (births)

$\%$ corporate

$\%$ in dirty counties

avg. real value of sales

(millions of ' 87 \$)

corporate

non-affiliates

avg. employ

corporate

all corp. births**

(1000's '87 \$)

total real value of equip. $\quad 258$

total employ

$\%$ plants inspected

'85-'92**

$\% 1965$ plants surviving

to ' 92

191

87

3.3

304 $\underline{1977-82}$

$\underline{1987-92}$

865

$58 \%$

$60 \%$

246

28

57

204

41

59

72

2.8

95

5.3

207

214

406

438

$\begin{array}{ll}-- & 20\end{array}$

$\begin{array}{ll}-- & 56\end{array}$

\section{METAL CONTAINERS}

stock of plants

$\%$ corporate

new plants (births)

$\%$ corporate

$\%$ in dirty counties

avg. real value of sales (millions of '87 \$)

corporate

non-affiliates

avg. employ

corporate

all corp. births"*

(1000's '87\$)

total real value of equip. $\quad 96$

total employ

$\%$ plants inspected

547

$76 \%$

178

60

68

31

179

'85-'92

$\% 1963$ plants surviving

to '92
564

$71 \%$

478

$65 \%$

148

39

67

120

38

63

39

2.3

3.4

139

116

95

130

27

31 


\section{Table 1 -- Size and Composition of Industries (Continued)}

\section{PLASTICS}

$\underline{1967-72}$

7608

$26 \%$

4082

new plants (births)

$\%$ corporate

$\%$ in dirty counties

avg. real value of sales

(millions of ' 87 \$)

corporate

non-affiliates

avg. employ

corporate

all corp. births *

(1000's '87\$)

total real value of equip.

total employ

$\%$ plants inspected

'85-'92*."

$\% 1963$ plants surviving

to '92

stock of plants

$\%$ corporate

new plants (births)

$\%$ corporate

$\%$ in dirty counties

avg. real value of sales

(millions of ' 87 \$)

corporate

non-affiliates

avg. employ

corporate

all corp. births**

(1000's ' $87 \$$ )

total real value of equip. $\quad 9.5$

total employ

$\%$ plants inspected

'85-'92**.

$\% 1963$ plants surviving

to ' 92

2339

$16 \%$

1300

8.9

63

13 $\underline{1977-82}$

11630

$25 \%$

4524

17

67

9.7

1.4

103

32

48

2.4

54

\section{WOOD FURNITURE}

2600

2783

$14 \%$

$11 \%$

1318

4.6

57

1279

4.5

48

11

17

$.93 \quad .95$

232

254

9.6

14

49

- Counties which are in non-attainment in all of ' $78,{ }^{2} 82$, and ' 87.

- Capital stock numbers here are largely imputed by the Census Bureau.

“* This ratio is the total number of plants reported in the EPA database (County Point Source Summary (AFP649)) as having at least one inspection from ' 85 -' 92 divided by the 1987 stock of plants. For the four industries respectively, the ratio of plants which were class A polluters in that sample for $\mathrm{VOC}$ or $\mathrm{NO}_{\mathrm{x}}$ emissions relative to the ' 87 stock are $12,14,0.7$ and 5.0 percent and the ratio of class A polluters relative to the ' 87 stock of corporate plants are 20,21, 2.6 and 42 percent. 
and wood furniture are bigger industries nationally in terms of employment than industrial organic chemicals and metal containers. And there has been rapid growth in plastics. On the other hand, plant sizes in terms of sales and capital to labor ratios are much larger in industrial organic chemicals and then metal containers, than in plastics and wood furniture. The corporate sector plays a dominant role in industrial organic chemicals and, to some extent, metal containers, compared to plastics and wood furniture. Corresponding to size differences, we note that plant inspections are much more likely in industrial organic chemicals and metal containers. In all industries, corporate plant sales are much larger than non-affiliated plant sales with ten or more differences. In terms of our hypotheses concerning big plants and plants in industries where the corporate sector is more highly regulated than the non-affiliated sector, we expect these to apply mostly to industrial organic chemicals and metal containers. In terms of other hypotheses we will refer to Table 1 at various points throughout the paper.

Data. Plant and industry data come from the Longitudinal Research Database [LRD], available through the Center for Economic Studies of the US Census Bureau. The LRD links data on firms and plants over time. For births and size analyses, we focus on data from the Census of Manufacturers conducted every five years (more specifically 1963, 1967, 1972, 1977, 1982, 1987 and 1992), to comprehensively track plants in the USA, albeit in five-year intervals. The Census data link plants to firms and follow plants over time. The Census is a Census of establishments - of physical buildings. Each structure (or set of structures) - a plant - devoted to manufacturing is assigned a permament plant number (PPN). The plant retains that PPN and is "alive" as long as the building remains active in manufacturing. A birth is either the construction of a new plant, a reopening of a manufacturing plant that was closed ("boarded-up") in the prior Census, or a conversion of an establishment from service or residential use to manufacturing use. Relocators (who are not identified) are births. Plants switching from one SIC classification to another are not births. 
Our geographic unit of observation is the county: Since 1978, attainment status is defined by county each year in the Code of Federal Regulations (although some northeastern coastal states classify all counties within a state with the same attainment status). For ozone, generally, either a county is in attainment or not of primary national air quality standards. There is no secondary standard for ozone. While there is a designation of partial attainment (widely used in classification for particulates and sulfur oxides), for ozone only a handful of counties are listed as partial attainment and most of these are large California counties with the worst air quality readings in the nation. We treat them as non-attainment counties. For the early 1970's, attainment status is defined nationally for 247 Air Quality Control Regions. We do the appropriate mapping of regions to counties, defining counties in "priority one" regions as non-attainment.

For estimation, we need data on county economic characteristics over time. Arnie Reznek of the CES kindly provided LRD-derived data on county manufacturing employment, wages, and salaries. Combining this data with data on our industries of interest, we can calculate the prevailing hourly wage and total overall employment, outside the own industry in manufacturing. Sample size is restricted to counties with data not subject to censoring (for disclosure reasons) for overall manufacturing by the Census Bureau, since wage information for those counties is likely to be based on just a few observations. For industrial organic chemicals, for example, that reduces the total county sample size by $9 \%$ in the birth models. Wages are deflated by the output price index for each of our industries from the NBER Manufacturing Producitivity Base by E. Bartelsman and W. Gray, resulting in a real wage in output units. Later in the paper, total value of sales is deflated by the same price deflator. Investment and book value of new born plants is deflated by the producer price index for machinery inputs to the relevant industry (e.g., for industrial organic chemicals, chemical industry machinery (commodity group 1166-04)).

Methodological Issue. 
In this paper, whether looking at births, deaths or sizes, the impacts of regulation are going to be inferred from comparing outcomes in non-attainment with attainment counties. Since generally we will use fixed effects methods, the "treatment group" are counties which are designated non-attainment starting in 1978 (and possibly priority 1 in 1972) or which switch in later years from attainment to non-attainment status. The "control group" are all counties historically (1963 up to 1972 or 1978) plus attainment counties in the regulatory era. Inferences are based primarily on how activity in non-attainment counties reacts to the imposition of regulation, compared to how it reacts in attainment counties. Such inference probably understates the overall impact of regulation per se, because for larger plants and with time, regulation affects activity in attainment areas as well. We do study patterns in time dummies to argue certain overall regulatory impacts; but we recognize that assessing specific impacts from time dummies is more an exercise in persuasion, than presentation of hard evidence!

In terms of treatment and control group issues, readers may be concerned that our sample of industries itself is only a treatment group. Henderson (1996) explicitly contrasts treatment and control group industries in examining location patterns of the stock of polluting industries for 1978-1987 (where, in that time frame, regulatory impacts come only from switches in attainment status). Thus we didn't feel the need, a priori, to have a control group of industries per se. We do have inadvertently one control industry, plastic materials and resins (SIC 2821 and 2822), which we requested data on originally, because it appeared on EPA "hit lists" in the 1970's. However, in EPA (1995), it is not recorded as a major VOC emitter. We estimated birth models (see below) for this industry finding no effects of regulation, in contrast to our industries. Additionally, our four industries are different from each other and each are divided into corporate and non-affiliated sectors. As we will see, regulatory effects differ in ways that our consistent with inter and intra industry differences. That is, our treatment group is heterogenous and treatment effects vary predictably with observed sources of heterogeneity, providing within group controls. 


\section{Births and Deaths in Polluting Industries}

In this section, we estimate econometric models of births and deaths of plants to evaluate our hypotheses concerning the locational shift from non-attainment to attainment areas, the timing of that shift, relative expansion of the non-affiliated sector under regulation, and survivals of new plants.

\section{Modeling Births}

For the birth process in each county, we adapt the stock model in Henderson, Kuncoro, and Turner (1995) to a flow (gross births) situation. For each separate industry, at a point in time, there is a supply of entrepreneurs in each county who might enter this industry (as opposed to entering other local industries or not starting a new plant). This supply relationship to a county is upward sloping in "births" (gross flows) and "expected per plant net present value" [NPV] space. Moving up the supply curve, the higher NPV's, the more local entrepreneurs will enter this industry. The curve may shift outward, say, as county size (e.g., total employment or population) increases. In terms of the opportunities for new plants, there is a corresponding "demand" curve, representing how per plant NPV's change locally with additional births in the county. The demand curve may be locally upward (local industry external scale economies) or downward (competition in local output markets) sloping. (Henderson (1994) finds plants operate on the downward sloping portion of inverted U-shaped profit (demand) functions.) The demand curve shifts up/out as real wages fall, county sizes increase representing local product demand increases, or county regulation weakens.

Total births are given by the intersection of the demand and supply curves, in birth - NPV space. This gives a reduced form equation

$$
B_{j t}=B\left(Y_{j t}, f_{j}+e_{j t}\right)
$$

where $B_{j t}$ is births in county $j$ in time $t . Y_{j t}$ is a vector of county characteristics including attainment status, as well as year dummies. $f_{j}$ is a county fixed effect of unmeasured time 
invariant features of the county affecting births in the industry, and is potentially related to the measured county characteristics. $e_{j t}$ is a contemporaneous i.i.d. error term. In general, regularity (i.e., a "stable" intersection of supply and demand) requires the sign of $\partial B_{j t} / \partial Y_{j t}$ to be the same as the sign of the partial derivative of the potential per plant NPV's to be earned (demand curve) with respect to $Y_{j t}{ }^{2}$

There are three issues concerning this birth model. First, NPV opportunities and births are not unrelated to existing stocks (which potential plants take as given). One could condition on existing stocks; but, in a panel framework, where stocks evolve through births (ignoring deaths), that leaves us with prior period births explaining this period births. Alternatively viewed, suppose we go back to the first period, $t=0$, the industry is in the county. Those births and the initial stock are determined by $Y_{j 0}, f_{j}, e_{j 0}$. In the next period, births are determined by $Y_{j 1}, f_{j}, e_{j 1}$ and prior stock, or $Y_{j 0}, f_{j}, e_{j 0}$. Proceeding forward, births in period $t$ are a function of $\left(\left\{Y_{j 0}, Y_{j 1}, \ldots Y_{j t}\right\}, f_{j},\left\{e_{j 0}, e_{j 1}, \ldots e_{j t}\right\}\right)$, where the $Y_{j}$ 's are highly correlated over time and may be strongly affected by the $f_{j}$. That is, in panel data set estimation with fixed effects, the $f_{j}$ essentially control for history and accumulated stocks. In estimation, we report results on equation (1) as formulated. Including lagged regressors $\left(Y_{j, t-1}\right)$ results in insignificant coefficients for those regressors.

The second issue of concern is that this "partial equilibrium" model of county births best fits a situation where plants are single-plant firms of local entrepreneurs deciding whether to enter this or some other industry locally. In multi-plant firms, corporate headquarters may scan the entire US geography to pick a profit-maximizing location in, say, a conditional logit framework. Later in this section we estimate conditional logit models for corporate births and compare results.

The final issue concerns the nature of births in the data. We observe six periods of

${ }^{2}$ If $\pi\left(Y_{j t}, B_{j t}, \delta_{j t}\right)$ is the demand relationship and $\tilde{\pi}\left(Z_{j t}, B_{j t}, \epsilon_{j t}\right)$ the supply relationship, where $Z_{j t}$ is a subset of $Y_{j t}$, then $\partial B_{j t} / \partial y_{j t}=\left[\partial \pi / \partial y_{j t}\right] /\left[-\partial \pi / \partial B_{j t}+\partial \tilde{\pi} / \partial B_{j t}\right]$ where the numerator must be positive under regularity. For a common element $Z_{j t}$, such as county scale, $\partial B_{j t} / \partial z_{j t}=\left[\partial \pi / \partial z_{j t}-\right.$ $\left.\partial \tilde{\pi} / \partial z_{j t}\right] /\left[-\partial \pi / \partial B_{j t}+\partial \tilde{\pi} / \partial B_{j t}\right]$, where we expect $\partial \tilde{\pi} / \partial z_{j t}<0$. 
births (from 1963-67 births to 1987-92 births). The number of births per county typically is a small number. For example, for counties which ever have births in industrial organic chemicals from 1963 to 1992 , the numbers of counties with $0,1,2,3, \ldots, 10$ births in 1982 were $263,123,19,5,2,1,0,1,0,0,1$ respectively. Thus, not only are births a discrete number, but in any period there are many zeros. Therefore, a sequence of births for a county over the six periods might be $\{1,2,0,2,1,0\}$. A formulation allowing for (a) discreteness, (b) zeros, (c) positive numbers close to 1 and (d) consistent estimates with fixed effects is suggested. A version of the Poisson seems a natural choice; and it is conceptually consistent with the county partial equilibrium framework.

To estimate (1), we utilize the conditional Poisson model in Hausman, Hall, and Griliches (1984) (see Anderson (1972) on conditional maximum likelihood), with robust standard errors (Wooldridge (1991) and Papke (1991) - robust to violation of the Poisson assumptions of equality of the mean and variance of the distribution). In the basic Poisson model, the probability of observing $B_{j t}$ births in county $j$ at time $t$ is

$$
\operatorname{Prob}\left(B_{j t}\right)=\frac{e^{-\lambda_{j t}} \lambda_{j t}^{B_{j t}}}{B_{j t} !}
$$

where $\lambda_{j t}$ is the Poisson parameter - the expected value of $B_{j t}$. In the conditional estimator with panel data, a common form for $\lambda_{j t}$ is

$$
\lambda_{j t}=e^{Y_{j t} \alpha+f_{j}}
$$

where $Y_{j t}$ are our exogenous variables, $\alpha$ the parameter vector, and $f_{j}$ the county fixed effect. The last represents time invariant unobserved county determinants of birth, and introduces some commonality in the conditional means of a county over time.

In estimation, the fixed effect is conditioned out by modelling the event in the likelihood function as the sequence of births in a county over time, conditional on total births for that 
county over time. Evaluating this gives us, as an event in the likelihood function, ${ }^{3}$

$$
\operatorname{Prob}\left(B_{j 1}, B_{j 2}, \ldots B_{j T} \mid \sum_{t=1}^{T} B_{j t}\right)=\Pi_{t=1}^{T}\left[\frac{e^{Y_{j t \alpha}}}{\sum_{s=1}^{T} e^{Y_{j \circ \alpha} \alpha}}\right]^{B_{j t}} \cdot \frac{\left(\sum_{t=1}^{T} B_{j t}\right) !}{\Pi_{t=1}^{T}\left(B_{j t} !\right)} .
$$

The log likelihood function for this situation is globally concave.

Issues in estimating (4) are goodness-of-fit measures and specification tests. For goodness-of-fit we use an $R^{2}$ type measure. Since we can't predict a county's expected births because $f_{j}$ 's aren't estimated, we predict its pattern of births over time, given its total births. In particular,

$$
R^{2}=1-\frac{\sum_{j=1}^{N} \sum_{t=1}^{T}\left(B_{j t}-E\left[B_{j t}\right]\right)^{2}}{\sum_{j=1}^{N} \sum_{t=1}^{T}\left(B_{j t}-\bar{B}\right)^{2}}
$$

where

$$
E\left[B_{j t}\right]=\left(\sum_{s=1}^{T} B_{j s}\right) \cdot\left\{\frac{e^{Y_{j t} \hat{\alpha}}}{\sum_{s=1}^{T} e^{Y_{j, \hat{\alpha}}}}\right\}
$$

Note $E\left[B_{j t}\right]$ is based on actual total births in $j$ multiplied by the predicted proportion occurring in $t$. The $\alpha$ coefficients in (4) are consistently estimated, as long as the conditional mean is correctly specified and the true distribution is linear expotential, even if it isn't Poisson. Wooldridge (1991) devises a Hausman statistic to compare the Poisson estimated parameters with other consistent estimates from nonlinear least squares. In our estimations the $\chi^{2}$ statistic is sometimes close to the $5 \%$ critical value; but failure never occurs when we segment the sample into corporate vs. non-affiliate births.

3

$$
\operatorname{Prob}\left(B_{j 1}, \ldots B_{j T}\right)=\frac{e^{-\sum_{t=1}^{T} \lambda_{j t}} \Pi_{t=1}^{T} \lambda_{j i t}^{B_{j t}}}{\Pi_{t=1}^{T}\left(B_{j t} !\right)}
$$

and

$$
\operatorname{Prob}\left(\sum_{t=1}^{T} B_{j t}\right)=\frac{e^{-\sum_{t=1}^{T} \lambda_{j t}}\left(\sum_{t=1}^{T} \lambda_{j t}\right)^{\sum_{t=1}^{T} B_{j t}}}{\left(\sum_{t=1}^{T} B_{j t}\right) !} .
$$




\section{Birth Results.}

In examining births, we focus on three hypotheses derived from the earlier discussion of regulation effects. These are (1) plant births will drop in non-attainment and rise in attainment areas, with the shift depending on the extent to which a county is out of attainment, (2) with the advent of regulation, the timing of the shift depends on the industry and plant sizes within industries, occurring earlier for bigger, more visible plants, and (3) small nonaffiliate plants may prosper at the extense of the bigger more visible corporate plants in the regulatory era. Tables A1 to A4 in the Appendix contain the conditional Poisson estimates for the four industries. Each table has four columns, two for all births, and one each for the sample split into corporate and non-affiliated sector births. Note, for each column, the sample size is the number of counties $(N)$ ever having any births for that sector in the six time periods $(T)$. Column 1 is for all births, with the non-attainment dummy constrained to have the same coefficient for 1978,82 , and 87 non-attainment status applied to $1977-82$, 1982-87, and 1987-92 births respectively. Columns 2-4 for all, corporate and non-affiliated births allow the non-attainment dummy coefficients to vary across time periods and adds in 1972 priority 1 status as an early measure of non-attainment. In the tables, births in, for example, 1982-87 are manufacturing plants not existing or operating in 1982 which appear in the industry in 1987. Explanatory variables such as wages, county scale as measured by total manufacturing employment, and non-attainment status are base period measures e.g., 1982 measures for $1982-87$ births.

Our focus is on non-attainment and time dummy variables in each column, the results of which are summarized in Tables 2 and 3 in the text. In the Appendices, we note that the measure of county scale - the log of total manufacturing employment outside the own industry - generally raises births noticeably. Looking at column 1 coefficients on county scale in Tables A1 to A4, coefficients may be interpreted as elasticities (given $\lambda_{j t}=e^{Y_{j t} \alpha+f_{j}}$ ), so a $1 \%$ increase in county employment leads to a $.17 \%$ to $.46 \%$ increase in expected births, depending on the industry. For real wages, only for industrial organic chemicals does the 
coefficient have some degree of significance where the elasticity is -.83 .

We now turn to our central results on the impact of regulation on the timing and location of plant births. The raw numbers back in Table 1 suggest a decline in the percent of births occurring in "dirty" (consistently non-attainment) counties following regulation, in all industries. Between the preregulation era (67-72) and the 1990's, there is an absolute drop of five to fifteen percentage points of births (between 67-72 and 87-92) occurring in dirty counties, even though there is no shift in overall economic activity out of such counties (Henderson, 1996).

The Poisson model quantities the effect of regulation per se. In Table 2, part a, the relevant coefficients for column 1 results in Tables A1 to A4 are presented. Non-attainment status in the regulatory era reduces births by $26-45 \%$ depending on the industry, with the largest impact being for the industry with the largest plant sizes, industrial organic chemicals. ${ }^{4}$ These are very large impacts, making the case that non-attainment became dramatically less profitable locations following regulation. While our estimating equation is reduced form, if the denominator of the $\partial B_{j t} / \partial y_{j t}$ expression in footnote 2 equals 1 , that implies regulation reduces NPV's by $26-45 \% .^{5}$ Regardless a significant welfare cost is incurred as plants shift from more efficient (non-attainment) to less efficient (attainment) counties, to be weighed against environmental gains.

In Table 2, the regulatory variable is a 0,1 indicator for non-attainment status, based in part on the notion of regime switches in terms of equipment regulation (LAER vs. BACT). However non-attainment areas which are more out of compliance face greater relative emission reductions. It seems likely that new plants in those areas would expect to face stronger

\footnotetext{
${ }^{4}$ For commercial printing, the non-attainment dummy coefficient is -.219 with a standard error of .166 . For this industry, for corporate versus non-affliates, there is rapid expansion of the non-affliate sector since 1972 and non-attainment effects are present in 1982 and 1987 in both sectors.

${ }^{5}$ That is, we are treating $\pi(\cdot)$ and $\tilde{\pi}(\cdot)$ as double log functions, where elasticities of aupply $(\partial \tilde{\pi} / \partial B \leq 0)$ and demand $(-\partial \pi / \partial B \geqslant 0)$ sum to one). If the supply curve is horizontal $(\partial \tilde{\pi} / \partial B=0)$ and the demand curve modestly downward sloping, then the sum can be quite small. On the other hand, for Brazil, Henderson (1994) finds supply curves to different industries to have slopes (point estimates) of 1.4 to 2.3.
} 


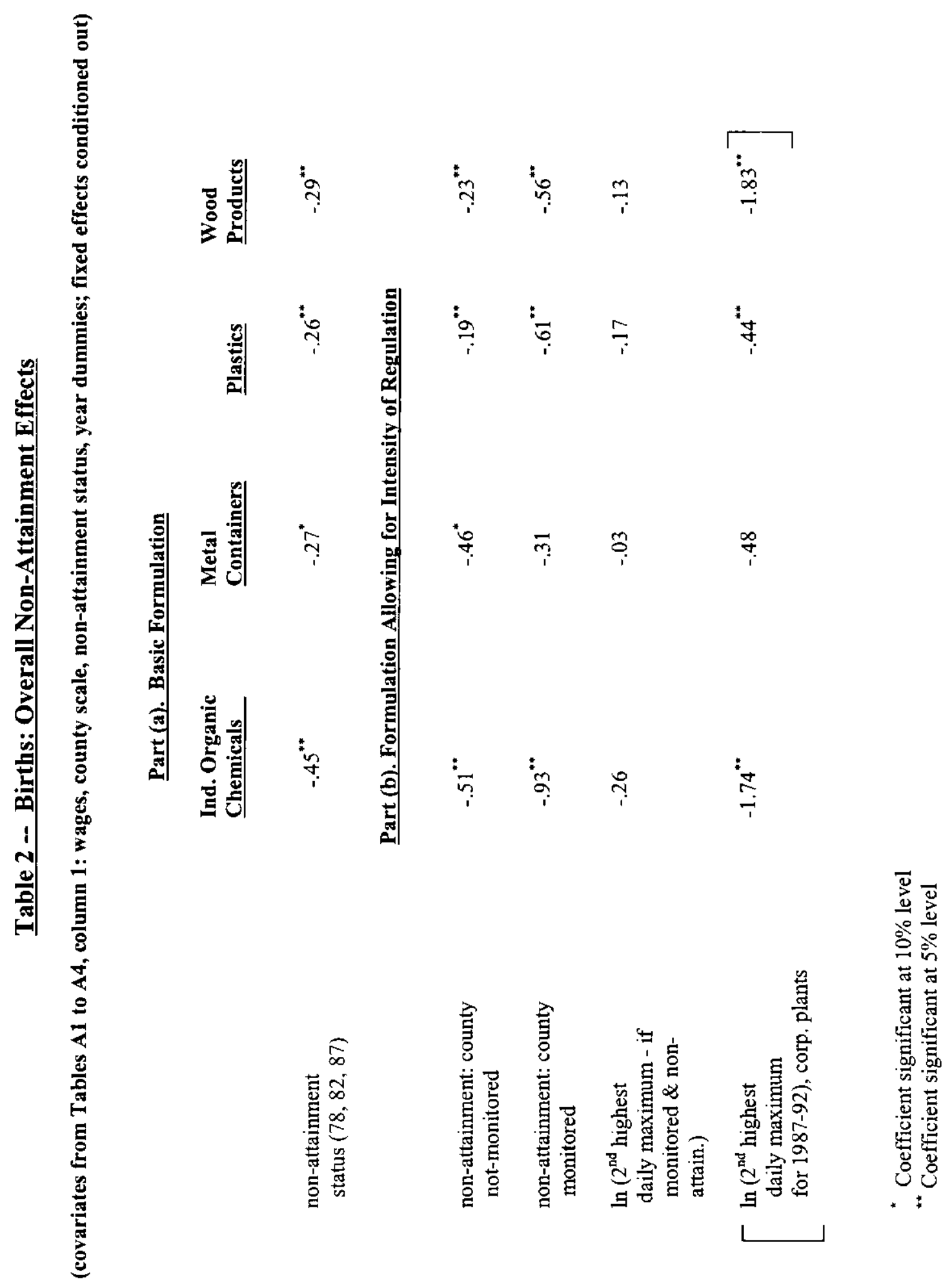


effective technology requirements on new equipment and, later, greater monitoring activity. To test for intensity effects, whereby a greater extent of non-compliance further reduces profit opportunities and births, we introduce two measures of regulatory intensity, into the column 1 Poisson models in Tables A1 to A4. First is whether a non-attainment county is currently monitored in the base year (1977, 1982, and 1987), noting that a number of non-attainment counties (especially in the North-East) are not routinely monitored. Being monitored is an indicator of both degree of non-attainment and general regulatory seriousness for that county. Second, if a non-attainment county is monitored, we interact that status with a measure of its degree of non-attainment. For the last, we use the county's annual air quality reading (for the base year) upon which non-attainment status is based - the second highest daily maximum hourly reading. Being more out of compliance, given a county is already sufficiently out to warrant monitoring, should induce greater regulatory activity, further reducing births.

In Table 2, part (b), we report just the attainment status and regulatory variables in this respecified version of column 1, Tables A1 to A4. In Table 2, non-attainment status, monitored or not reduces births. The first question concerns whether those non-attainment counties which are monitored have greater birth reductions than those which are not monitored. In the three cases where both coefficients are significant, those counties which are monitored experience noticeably greater birth reductions. Second, given monitoring, we note that the coefficients on the log of the second highest daily maximum reading are negative, as hypothesized, but are never significant. We did break the evaluation up into corporate and non-affliate sectors by year (see Table 3 next). For the final year, 1987-92, for the corporate sector, effects of the second highest daily maximum are much stronger. For the four industries, in the last row of Table 2, a $1 \%$ increase in the second highest daily maximum reading reduces births by .44 to $1.8 \%$. In summary it appears intensity matters.

Having established that non-attainment status affects location, we now investigate how the effects vary by industry, time, and corporate versus non-affliate plants. Details on 
these results are in columns 2-4 of Tables A1 to A4. In the text, in Table 3, we focus on the Census by Census non-attainment states and time effects on the four industries, with the samples split into corporate versus non-affiliates. In examining Table 3, we will discuss three sets of results. First will be the timing of non-attainment status effects for corporate versus non-affliate plants. Second will be the timing of non-attainment status effects across and within industries generally, focusing on the corporate sector. Third will be overall time effects on births, apart from non-attainment status.

For the first, within each industry, as indicated by the circled pairs of coefficients, nonattainment status hits the corporate sector a Census before it hits the non-affiliate sector, with its smaller, less regulated plants. So the first significant negative coefficient on nonattainment status for corporate industrial organic chemicals appears for 72-77 births, while for non-affiliates it appears for 77-82 births. This exact pattern holds across all industries, except for wood products. For wood products, while non-affiliates first have a significant negative coefficient in the same time frame (82-87) as corporate plants, the initial coefficient for non-affiliates is relatively small $(-.27$ versus -.55$)$ and grows over time (from $-.27 \%$ to -.45) (all in absolute value terms). This time pattern of coefficients supports the view that large, more visible plants came under regulatory scrutiny earlier than small non-affiliates.

In terms of the second set of results on more general timing issues within and across industries, first in general, regulatory effects seem to take hold earlier in industries with bigger plants who are heavier polluters. So, earliest with strong impacts is industrial organic chemicals and second metal containers. Plastics and wood products either follow after metal containers or are more phased-in. But each industry has its idiosyncracies on timing which are of considerable interest.

In industrial organic chemicals, for 1972-77 births, for non-affiliates it looks like nonattainment status initially spurs births. That could be an anomaly, or it could be nonaffiliates moved in to fill the vacuum left by the corporate sector in non-attainment areas, in an era where non-affliates may have not foreseen current or future regulations affecting 


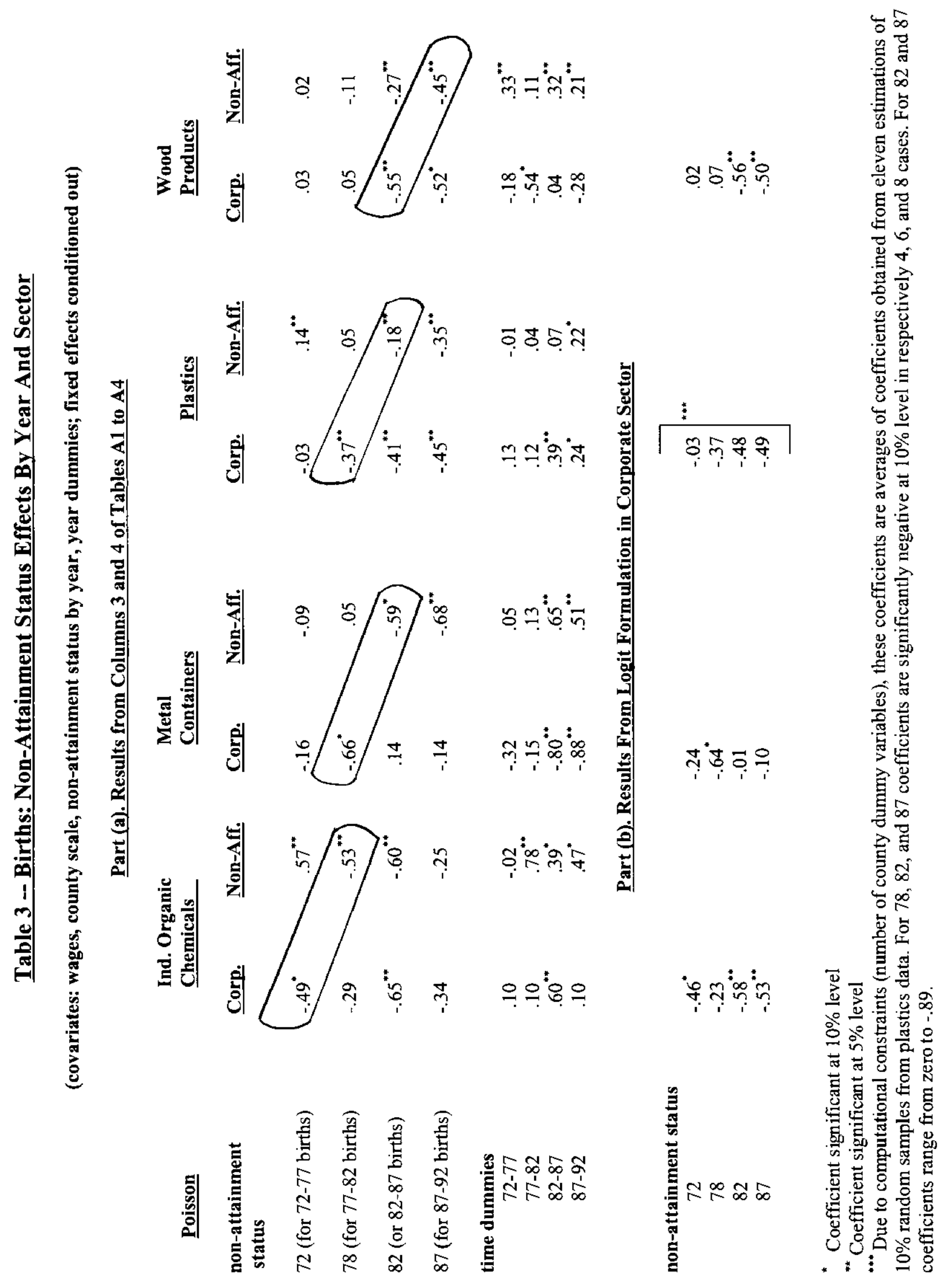


them. For industrial organic chemicals, it also looks like non-attainment status effects wane in the last time period (87-92). That could be possible: for example, green equipment in this early regulated industry could become cost efficient and standard everywhere, so the costs and choices of new plants would be less affected by non-attainment status. However, this waning does not occur for corporate plants in logit results discussed below.

For plastics and wood products, especially for non-affiliates, the impact of non-attainment status seems to grow stronger as we approach the present and these industries come under increasing scrutiny in non-attainment areas. For metal containers, for corporate plants, it looks like non-attainment status has no impact after 1977-82. We believe such an interpretation to be incorrect. As we will note momentarily, the corporate sector of metal containers appears to be dessimated by regulation, so that distinguishing between attainment and nonattainment areas is difficult. That is, in estimation, inferences are being based in later Censuses on a total of less than 40 corporate births, much less than other industries (in any Census).

The final issue concerns an overall shift in relative activity from the corporate to nonaffiliate sector in each industry regardless of county attainment status. We base our reading on an anlysis of the relative magnitude of time dummies in the corporate vs. non-affiliate sector within the different industries. As noted earlier, interpreting time dummies is an exercise in assertion as to causation. Nevertheless we tell, we think a plausible story. What we are looking for is a post regulation (72-77 or 77-82 onwards) pattern, where non-affiliate time dummies exceed those of corporate time dummies, relative to the pre-regulation base period (67-72) in the Poisson, indicating higher relative births in the non-affiliate sector. Except for the nationally rapidly growing plastics sector this appears to be the case. For industrial organic chemicals, metal containers, and wood products, in 10 out of 12 cases, the non-affiliate dummy exceeds the corresponding corporate dummy, in seven cases significantly. Two items stand out in the pattern. First for metal containers post 1982 births in non-affiliates jump $50-65 \%$ while in the corporate sector they fall by $80-90 \%$. This is the dessimation of the 
corporate sector in metal containers noted earlier, possibly caused by differential regulation. From Table 1 total births in metal containers in non-affiliates rise from 71 to $67-72$ to 90 in the 77-82 time period, falling back to 72 in 87-92. For corporate plants births decline from a pre-regulation (67-72) level of 106 to 58 in 1977-82 to 45 by 1987-92 (and fewer in our estimating samples). We interpret the initial decline in 1977-82, as a corporate response to Pindyck's "input cost" uncertainty in the early days of regulation and the later response (post 1982) as a reaction to "bad news" for corporate sector metal containers. Post 1982, perhaps due to environmental regulation, corporate production in metal containers remains relatively unprofitable compared to the past.

Similar considerations but different outcomes apply to industrial organic chemicals. In 1972-77 and 1977-82 births stagnant (actually decline in raw numbers) in the corporate sector, except here the post-regulation news is good and 1982-87 births rebound. More pronounced is the situation for non-affiliates. The early uncertain regulatiory period (197782) for non-affliates brings an explosion of births - the highest positive time dummy in Table 3 and in raw numbers a jump from 111 non-affiliate births in 1967-72 to 176 in 1977-82. Many of these births are in "experimental" attainment counties never having the industry before, as well as in non-attainment counties. The number of counties experiencing births rises from 106-120 in prior Censuses to 174 in 1977-82 with the number of "clean" counties (these in attainment in all of 1978, 1982 and 1987) experiencing births rising from 27 in 1972-77 to 64 in 1977-82 (before falling back to 46 in 1982-87). This may be a response to Pindyck's technical uncertainty, where small plants experiment to see to what extent they escape regulation, by investing in small operations. ${ }^{6}$ As we will explore shortly, the survival

\footnotetext{
${ }^{6}$ Based on capital stock numbers from the Census (largely imputed) among 1977-82 births, in attainment counties, new plants averaged 1982 capital (machinery and equipment) of $\$ 466,000$, while in non-attainment areas new plants averaged $\$ 1,247,000$. This threefold differential does not exist in other years. In 196772 , births in attainment counties averaged 578,000 in capital (in 1972) which was greater than those in non-attainment counties $(407,000)$. In 1982-87 again the differences in average capital stocks for births in attainment versus non-attainment counties were small $-\$ 6,165,000$ versus $\$ 7,038,000$ respectively. Many of the relatively large number of $1977-82$ births in attainment counties might be viewed as $1 / 2$ million dollar roles of the dice made to learn about environment regulation. (For the record we note for 1977-82
} 
rates of these 1977-82 experimenters are very poor, so that in fact, despite the explosion of non-affliate births in the early 80 's, by 1992 the share of non-affiliates in the total stock of plants is little changed (Table 1). Presumably the news for non-affliate experimenters wasn't great and post 1982 their share of births is similar to pre-regulation levels.

Birth Logits. In the beginning of this section we noted that the Poisson model of internal county generation of births may not be the best conceptual framework for corporate births. Rather a conditional logit model may be a more comfortable formulation, where, conditional on the number of national births, owners of new plants in an industry survey all counties and pick the profit-maximizing location for the plant. We estimated such a model for the corporate sector for our industries, where, in each of the six Census periods this experiment occurs, plants choose their best county, with county and time dummy variables across the experiments. Focusing on the key non-attainment variable in logits corresponding to column (3) of Tables 2-5, in part (b) of Table 3, we find that a switch to non-attainment status reduces the probability of a birth occurring in that county. The magnitudes of coefficients can be compared to those in part (a) of the table. Part (a) gives a percent change in expected number of births, whereas part (b) gives the percent change in the probability of a typical birth. The two sets of coefficients are similar with one exception. With conditional logits, in industrial organic chemicals for 1987-92 births, there is no tailing off in the negative nonattainment status effects. Non-attainment status reduces the probability of a birth by $53 \%$, comparable to magnitudes in other Census periods.

Survival of Births.

For the births just described, what can we say about their survival rates? Here we examine the five-year survival rates of cohorts of births, based on Probit estimation. In formulating the model, survival here means survival of the plant in manufacturing (even if it

births in attainment areas the 45 failures (to survive to 87 ) averaged the same capital stock $\$ 461,000$ as the 10 survivors $(\$ 486,000)$. In non-attainment counties the 50 survivors averaged $\$ 1,533,000$ compared to $\$ 1,045,000$ for the 71 failures.) 
switches SIC) in this location, given a birth here in the industry five years ago. A narrower alternative would be to require the plant to survive and stay in the same industry. Generally results are similar; here we stick to the "pure death" version. Recalling our discussion of the effects of regulation, we expect the following. In industries with large plant sizes and early imposition of regulation, we expect grandfathering of existing plants. So the 1967-72 pre-regulation wave of births should have high survival rates compared to the 1963-67 wave (surviving to 1972) in the pre-regulation era or compared to survival rates of later births waves under regulation. Similarly in industries with large plant sizes, in the later "mature" years of regulation we expect initial plant sizes to rise (as phasing-in of investments are de-emphasized under regulation). Thus, we expect survival rates to rise as firms select less risky start-ups, given higher investment commitments are involved. Finally, in industries where there are high birth rates of non-affiliates in the early years of regulation, many of these births may be "experimental" with poor survival rates.

We have a problem with sample size in estimation for most industries. Ordinary Probit results are problematical given persistence of unmeasured county attributes over time affecting survival rates. Thus we add county fixed effects for this pooled cross-section of five waves of births and survivals. Doing so cuts the sample by up to $40 \%$, eliminating all counties (1) which have only one birth over this period and (2) where all births either always die or always survive (since county fixed effects then tend to $\pm \infty$ ). This sample reduction eliminates some of the 1977-82 plant births in experimental counties in industrial organic chemicals, for example. Because of reduced sample size, we don't separately estimate survival probits for corporate and non-affiliates, except for plastics where sample sizes for both sectors are large. (Note for wood furniture, while there are high overall births for survival analysis, there are few corporate births.) Second, it is hard to distinguish attainment status effects by years; for some industries, some cells are not even identified. What we focus on is one overall survival probit for each industry (except for plastics with its large sample sizes for both the corporate and non-affiliate sector), corresponding to the column (1) formulation in 
Tables A1 to A4.

The basic Probits are given in Table A5, in the Appendix. The key feature is the statistical insignificance of most explanatory variables. For industries other than plastics, when we can split the industry into sectors or distinguish non-attainment status by years, the picture does not improve. The only uniform results are the following: (1) Corporate plants in all industries have significantly higher survival rates. (2) The non-attainment dummy is always positive, potentially supporting the idea that survival rates rise in nonattainment areas. They could rise both because of successive grandfathering effects in nonattainment counties as equipment regulations tighten over the years and because of better project selection under higher regulated initial investment lumps. Note, non-attainment could have the opposite effect on survival. Unanticipated regulatory "harrassment" in nonattainment could drive plants out of business prematurely. (3) 1972-77 and 1977-82 births in the early years of regulation generally have lower survival rates, again with varying degrees of insignificance, potentially supporting the experimentation hypothesis.

In Table A5, the strongest results are for industrial organic chemicals with its large plant sizes and early regulation and for plastics with its large sample sizes, while the weakest are for wood furniture, the industry with smaller capital investments. In fact, time and nonattainment variables for wood furniture are all essentially zero. Of the four industries, only for industrial organic chemicals and plastics do time and non-attainment variables as a group have any reasonable degree of significance (most t-statistics well over 1.0). In making these statements as applied to plastics, we are focusing on the results for the corporate sector. However, as noted below once we separate out non-attainment effects by year (Table A6), results for the corporate and non-affiliate sector of plastics are similar. For industrial organic chemicals and plastics, it seems reasonable to investigate whether our specific hypotheses hold. For the other two, survivals appear idioscynratic and modestly affected by regulation.

To examine results for industrial organic chemicals and plastics, we report estimated survival probabilities in Table 4 . In Table 4 we look at a corporate plant in a county 


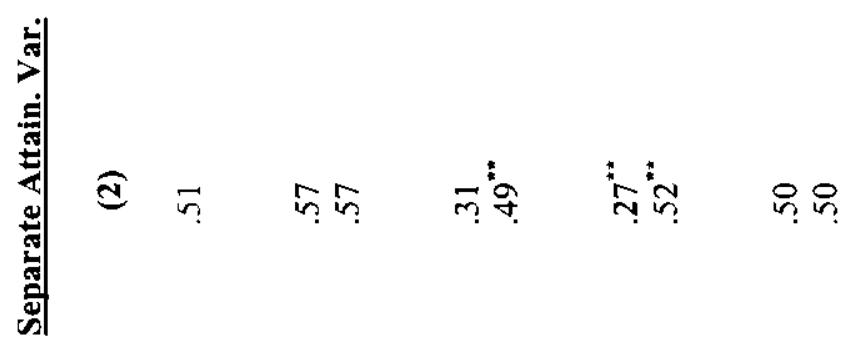

言
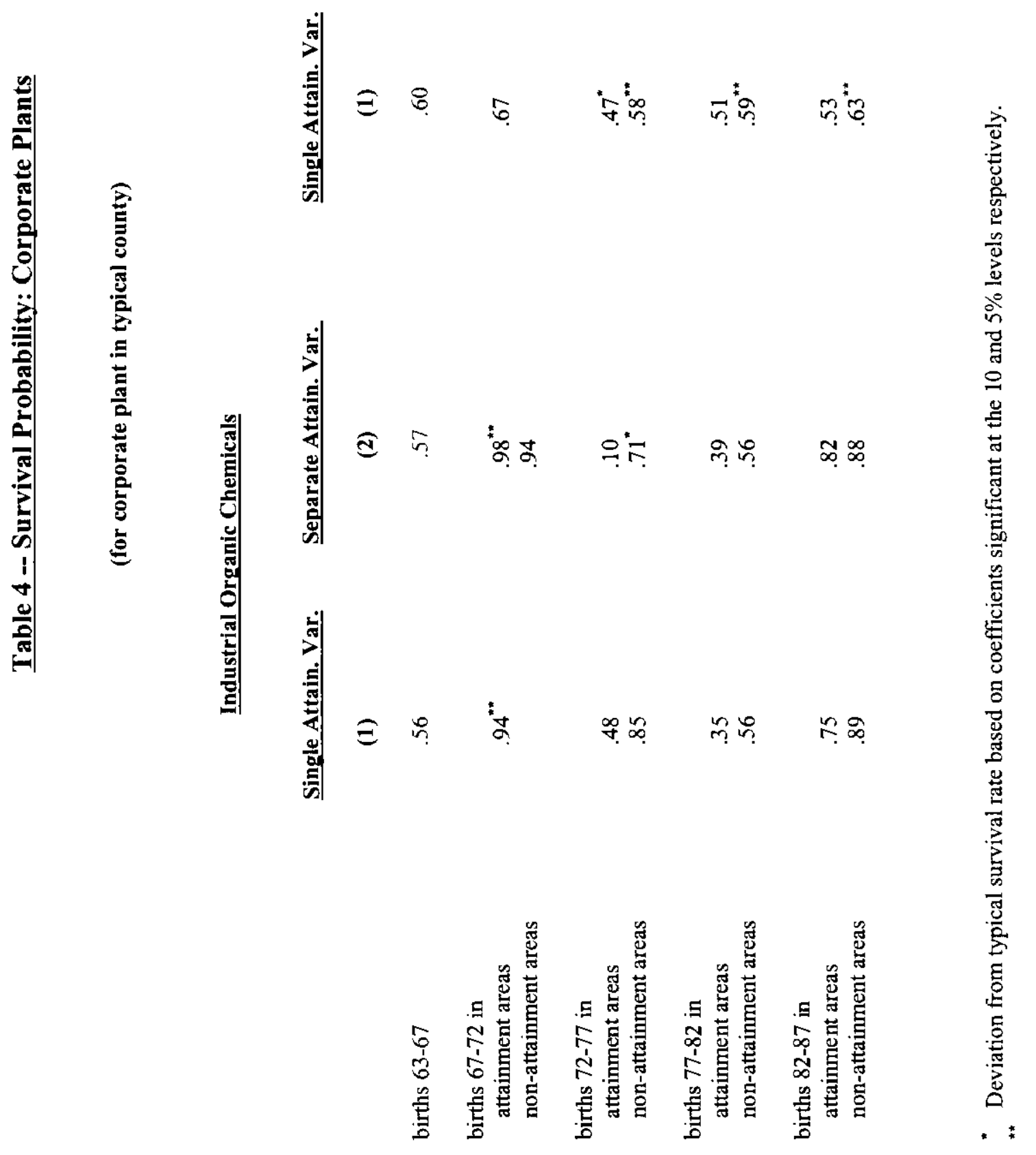
with average wages and total manufacturing employment. The survival probabilities for the 1963-67 birth cohorts jump in moving to the 1967-72 cohorts, substantially in industrial organic chemicals and less in plastics. This could be our hypothesized grandfathering effect, where with impending regulation on new producers, existing grandfathered plants stay put. With the advent of regulation (preliminary for 1972-77 births and full fledged for 1977-82 births), survival rates drop in attainment counties in both industries. For example, 1977-82 births, survival rates fall to $35 \%$ for these experimental burst of births in industrial organic chemicals, which we previously noted. In the "mature" years of regulation, for 1982-87 births, survival rates in attainment and especially non-attainment counties are higher again most noticeably in industrial organic chemicals. This supports our notation of higher survival rates for new large plants, with reduced phasing-in of capital investments under regulation.

For these industries, as reported in column (2), if we separate out non-attainment status by years, the calculated probabilities (based on Table A6 coefficients) are similar to those in column (1). For plastics, estimates became more precise with both time dummies and attainment status variables being significant for 1972-77 and 1977-82 births. In general, there becomes a wider divergence in survival probabilities between attainment and nonattainment areas in 1972-77 and 1977-82, with lowered survival probabilities for attainment areas. For industrial organic chemicals, if we break the industry into the two sectors, while non-affiliates have lower survival rates overall, the patterns in the two sectors are very similar: both exhibit grandfathering, poor survival rates in attainment counties in the early years of regulation, and high survival rates in the mature years of regulation especially in nonattainment counties. For plastics, while Table A5 suggests very weak effects overall for non-affiliates, Table A6 suggests stronger effects, similar to those for corporate plants.

\section{$\underline{\text { Summary }}$}

In all our polluting industries there has been a relative shift in births from nonattainment to attainment counties, with the magnitude of the shift out seeming to depend 
on the extent of non-attainment in a county. Within industries, the shift starts a Census period earlier for corporate relative to non-affiliate plants; and, across industries, appears to start earlier for industries with bigger plant sizes. Overall there is a shift in births from the more regulated corporate to the less regulated non-affiliate sector, in all industries except plastics. In metal containers, the shift is strong and corporate births remain low throughout the regulatory period, effecting a strong shift in stocks. For industrial organic chemicals, while there is an initial explosion of "exploratory births" of non-affiliates in attainment areas, these have very poor survival rates. Also corporate births rebound relatively in the later years of regulation. As a result corporate shares of plant stocks and employment are almost the same in 1992 as in 1972.

Survival probits perform disappointingly for all industries, with the strongest results for industrial organic chemicals with its large plant sizes and plastics with its large sample sizes. For those industries, there is evidence of grandfathering of existing plants, low survival rates of plants in the early exploratory years of regulation, and high survival rates in the later mature years of regulation.

\section{Plant Sizes and Timing of Investments}

In this section, we look at how plant sizes and investment patterns have changed in our four industries to try to see if and how regulation has affected plant sizes and investments. Back in Table 1, some basics are apparent. First, we look at plant production (real sales) in the corporate sector (to control for changes in industrial structure, given regulation may help non-affiliates). In all industries average per plant corporate sales rise from 1972 to 1992, so there certainly is no general downsizing. In 2-3 industries sales actually dip in 1982 (from 1972) before rising to 1992 , a feature we will comment on later. While per plant corporate sales are rising in three of four industries, per plant employment drops, especially in the big plant industries of industrial organic chemicals and metal containers. This suggests a rise in the capital to labor ratio, absent enormous productivity gains. Table 1 numbers on 


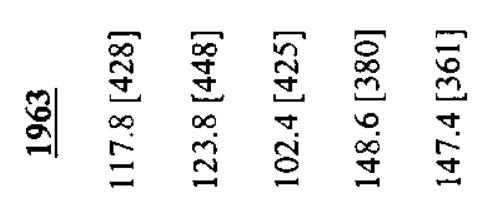

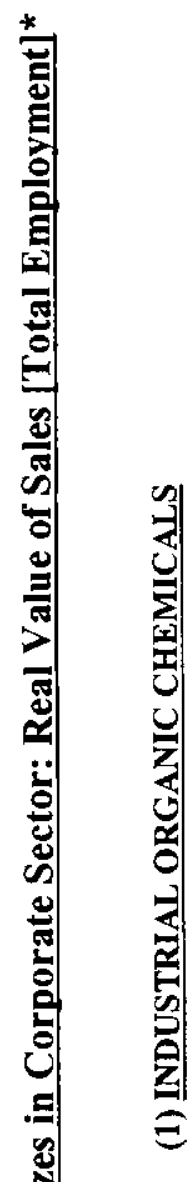

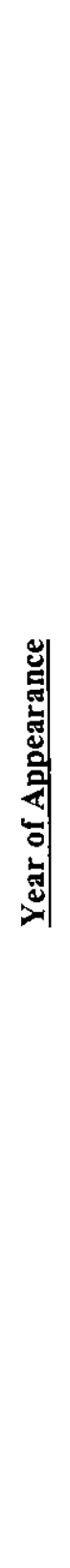

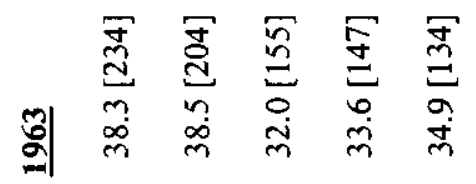
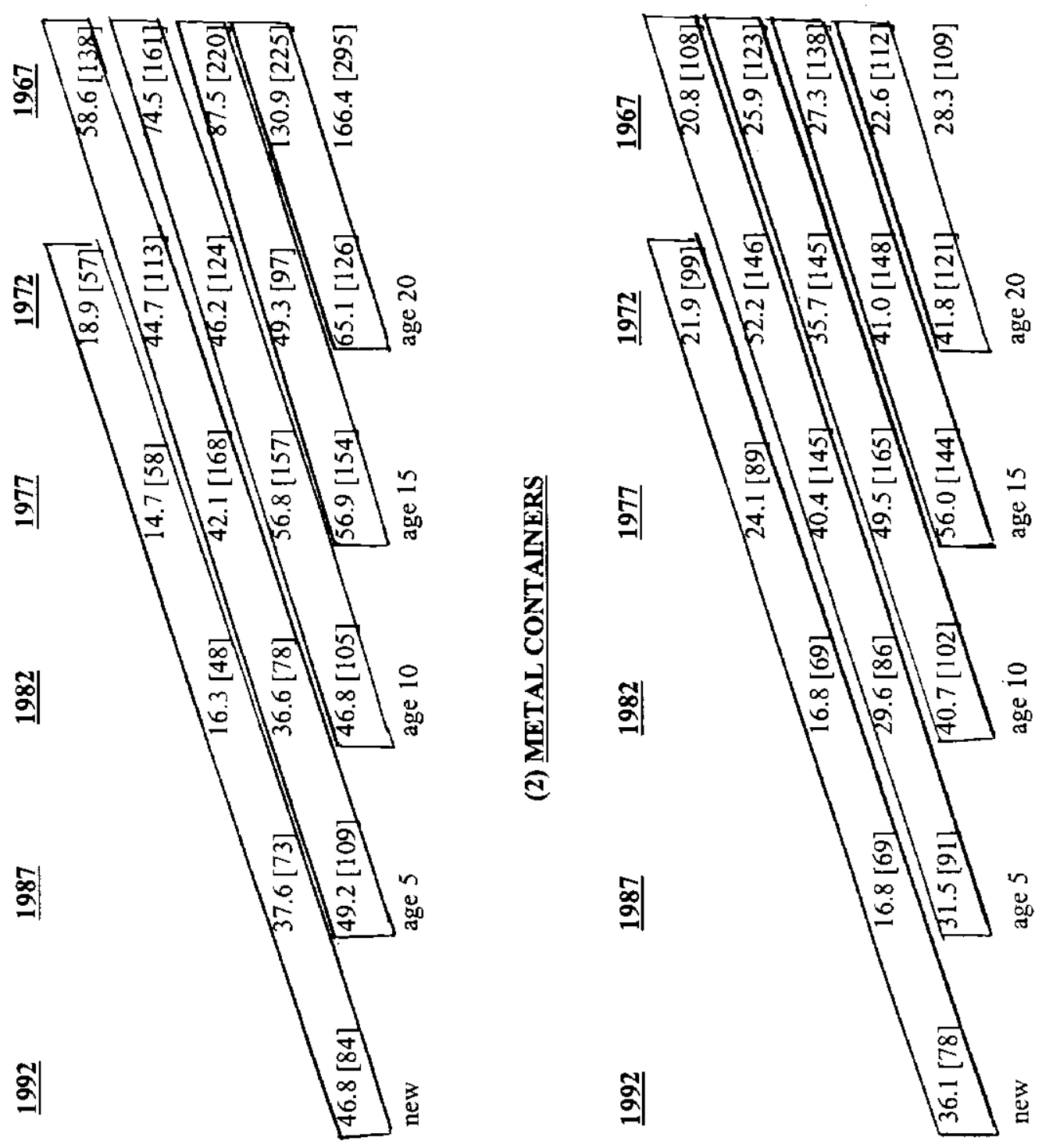

$$
\approx \approx \infty \leftarrow \alpha
$$$$
\approx \approx \infty \infty \approx
$$ 
资

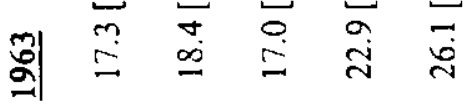

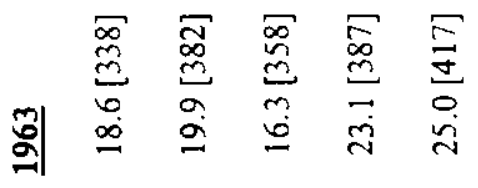

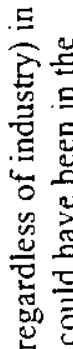

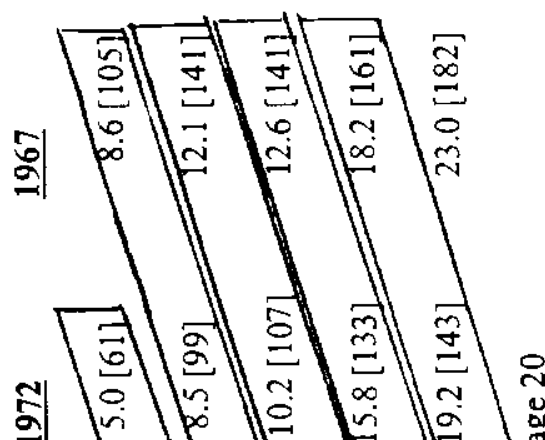

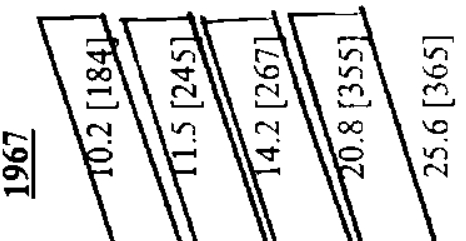

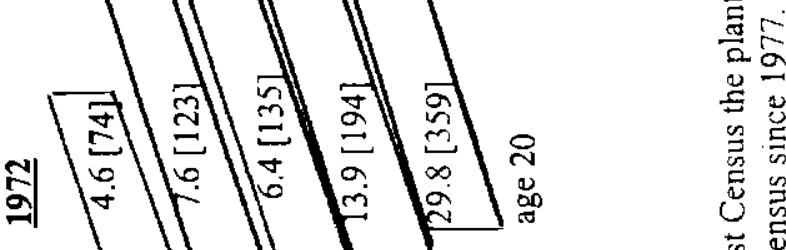

פิ

:

용

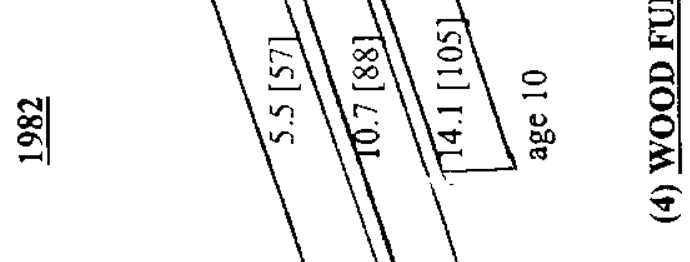

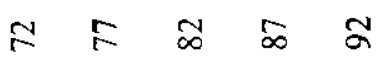

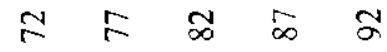

:

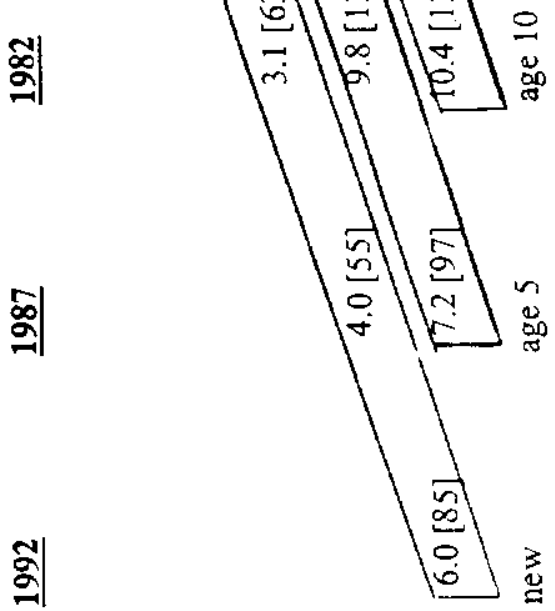

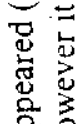

त्वि

苞过

娄

5

䓽志

$\because$ 胥

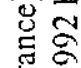

岁.

옹

跑苟

䒕

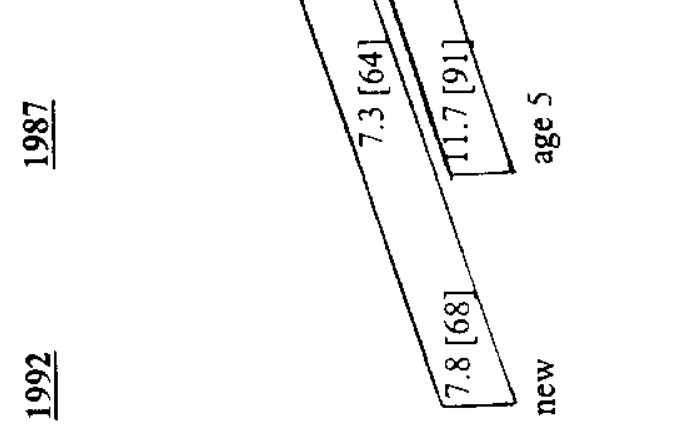

范

눙

$<$

蚍

品

岂茊

:

嵌 $\Xi \stackrel{9}{a}$

吾要

:

至总富

焉岂

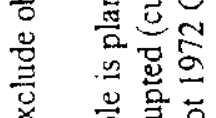

范苛

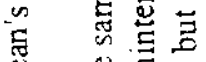

芩 
capital-to-labor ratios for new plants suggest such a rise occurred.

We start the section by returning to the question of whether regulation has affected plant sizes. We first note that the numbers in Table 1 mask possible changes in the age composition of industries, which could affect sizes. In general, older plants in an industry are larger than young ones, both because of selection (unhealthy plants which are typically smaller die out) and because of accumulated investment. To see if patterns emerge controlling for age, we turn to Table 5. In Table 5, except for 1963 stocks, each column is a year plants first appear - so 1967 is the year 1963-67 births appear. Each row is the year plant employments are observed (by year of birth) for plants still in operation in that year. Each column then shows how a birth cohort of plants grows in average size, as it ages. The diagonals as marked are particularly relevant. Each diagonal represents the average sizes of plants of similar age, by year of birth. So for the age 5 diagonal, 1967 births are 5-9 years old in 1972, just as 1987 births are 5-9 years old in 1992.

In Table 5, what patterns are common to all industries? Looking along the diagonals in the different age categories, no patterns common to all industries emerge, except in the new plant category. There in all industries, 1992 new plants are larger than new plants in all other years in the corporate sector. We will argue later than this outcome in fact is due to regulation. The other pattern common to all industries is that sales to labor ratios rise, controlling for age, suggesting capital to labor ratios may also rise. For example, just looking at historical 1963 plants, in the last column of the table, sales to labor ratios rise in all industries with time, usually fairly dramatically.

Apart from common patterns, there is one distinct industry specific feature in industrial organic chemicals. Controlling for age, plants born in 1967 are much larger than later born plants; and 1963 plants with no age controls are very large. In the age 5 to age 20 categories, 1967 plants are larger than in all other years. This suggests plant downsizing among postregulation plants. This is the industry with the largest plant sizes. In order to reduce risk of investment in any one location and/or to reduce regulatory scrutiny, it is not unreasonable to 
expect downsizing. The increased average corporate plant size in industrial organic chemicals appears to occur because old plants grow in size, and the introduction of new smaller plants doesn't offset this.

However, even asserting this for industrial organic chemicals is tentative. Table 5 is for plants in operation in the industry in the Census year; but they may have been in another industry in another Census year (and hence not part of the average for that other year). Plants switching in and out of industrial organic chemicals (unlike the other industries) play a critical composition role. In Table 6 , we look briefly at switchers in industrial organic chemicals. The early regulation years (relative to pre-regulation) see more and bigger plants switching out of the industry than previously, suggesting regulation may have induced more and bigger plants to switch out of the industry, helping to keep average plant sizes down. Similarly, the 1982-87 time period sees more deaths of bigger plants, again helping to keep average plant size down. Finally, sizes of plants switching into the industry seem to decline in the regulation era. Clearly, all this complicates the interpretation of raws number. It still, however, looks like existing older plants grew in size and surviving newer plants are smaller under regulation.

These size and age patterns in and of themselves don't give a clear picture of the impact of regulation. In part it is difficult to rely simply on a before and after general analysis of regulation. As earlier, we turn to an analysis of different impacts between attainment and non-attainment areas to assess the effects of regulation. We are asserting that the primary change over time in the industrial environment between attainment and non-attainment areas is the introduction (explicitly in the regulatory process) of much heavier regulation in non-attainment areas, controlling for county covariates.

To assess the impact of non-attainment status on size, we do regression analysis on plant sizes, measured by real value of sales. The basic formulation looks at plant sizes of all plants in each Census, excluding plants with just administrative records (i.e., plants in existence but whose sales are imputed, not surveyed). Eliminating administrative records 
Table 6 -- Switches and Deaths of Corporate Plants in Industrial Organic Chemicals

63-67

67-72

72-77

77-82

$\underline{\text { 82-87 }}$

87-92

Plants switching out: employment (number)

Deaths: employment (number)

Plants switching into industry: employment (number) $195(67)$

$157(27)$

$172(34)$

$295(54)$

$275(84)$

$218(66)$

$241(63)$

$52(48)$

$53(77)$

75 (49)

$55(77)$

$131(104)$

$73(84)$

231 (49)

$226(94)$

$171(87)$

$206(98)$

$138(63)$ 
leaves virtually all corporate plants but eliminates much of the smaller non-affliate sector. ${ }^{7}$ Consequently distinguishing between corporate and non-affiliate plants is no longer so important; more critically results for corporate versus all plants with non-administrative records are similar and we report just on the latter.

The size equation explains variation in the logarithm of real value of plant sales, with covariates being county characteristics (log of wages and of all other manufacturing employment), age dummies (age 5-9 years, and age 10+ years), a dummy for a corporate plant, non-attainment status information, and then year and county dummies (see below). Given size is contemporaneous, so are covariates. So 1982 size is a function of 1982 characteristics of the county and plant where 1981 attainment status marks 1982 conditions (status changes in July). There are only three age categories, since that allows us to start the plant observations in 1972, where all 1963 plants are "10+" years old (almost). If we added a category of 10-14 years (with then 15+ years), we would need either to drop all 1963 plants (since we couldn't tell if they were 10-14 or $15+$ years) or to start size regressions in 1977 , dropping 1972 plants and eliminating a comparison with the pre-regulation era. Based on three age categories, size regressions have as samples all plants observed in 1972, 1977, 1982, 1987, and 1992 in the Census, which are not administrative records. In contrast to this age formulation, we did also some cohort regressions, where each birth cohort is followed over time. Estimation is hampered by cell size problems (when in each Census year each cohort enters separately divided into attainment and non-attainment areas), which also can create disclosure problems. We do note some results from the cohort regressions, later on.

The focus of analysis concerns non-attainment status. It became clear early on that non-attainment status effects varied by age. So we have a dummy variable for all plants (the

\footnotetext{
${ }^{7}$ For two industries the corporate sample in OLS estimation for 1972-92 is entirely non-administrative records. The biggest deviator is plastics with just 9 out of 13,324 records being administrative for 1972-92 in the corporate sector. For all plants, the share of administrative records in all records in Census years 1972-92 is for industrial organic chemicals, metal containers, plastics, and wood products respectively $19 \%$, $16 \%, 33 \%$, and $48 \%$. These numbers already exclude records with zero sales.
} 
effect for new plants) in non-attainment areas, plants 5-9 years in non-attainment areas and plant $10+$ years in non-attainment areas. For older plants (10+ years), for example, the net effect of non-attainment status is the sum of the coefficients for all plants and plants $10+$ years in non-attainment areas.

In estimation we have a choice between OLS, county fixed effects and plant fixed effect. It is clear OLS estimates are problematical. Plant sizes and county characteristics (e.g., non-attainment status and wages) are related to county unobservables. Imposing county fixed effects has little impact on sample size (relative to OLS), only excluding plants in counties where only one plant ever appears just once. The biggest drop (wood products) is $5 \%$. Imposing plant fixed effects requires each plant to be in the sample for two Censuses, eliminating all newborn plants in 1992 (a key group) as well as many other newborn's in other years - resulting in drops in sample sizes of $24,17,28$, and $43 \%$ for industrial organic chemicals, metal containers, plastics, and wood products respectively. It appears results differ between county and plant fixed effect formulations because of the alteration of the sample (simple non-random loss of information). For example, results using just the plant fixed effect sample, for county and fixed plant effects formulations are similar; but results for county fixed effects between plant versus county fixed effect samples differ.

The results for the county fixed effect regressions are in Table 7 . We briefly comment on the covariates other than regulatory variables. County wage and scale covariates have little impact on plant sizes, indicating plant scale (vs. local industry scale) is little affected. Age dummies have expected strong effects. Plant sizes increase by $50-60 \%$ and then by about $100 \%$ in moving from a $0-4$ year age to a respectively $5-9$ and then $10+$ age category. Corporate plant sizes, ceteris paribus, are typically $130 \%$ larger than non-corporate plants in the sample.

Turning to non-attainment status effects in Table 7, (except for metal containers) there is a clear pattern. New plants (the all category) are significantly larger in non-attainment counties than attainment counties by $22-68 \%$. That effect then dissipates with age, so 


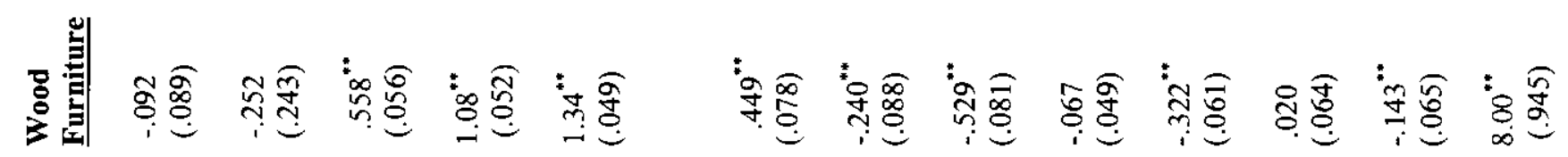

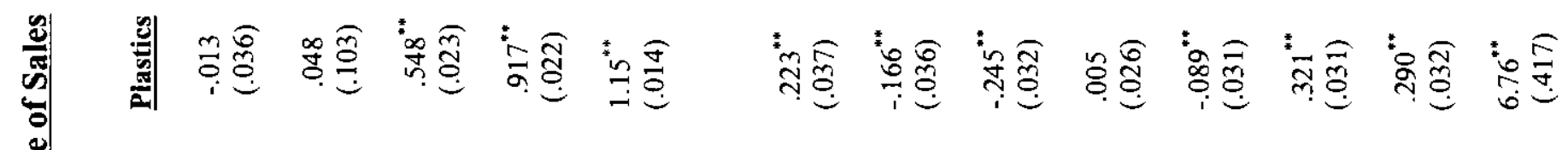

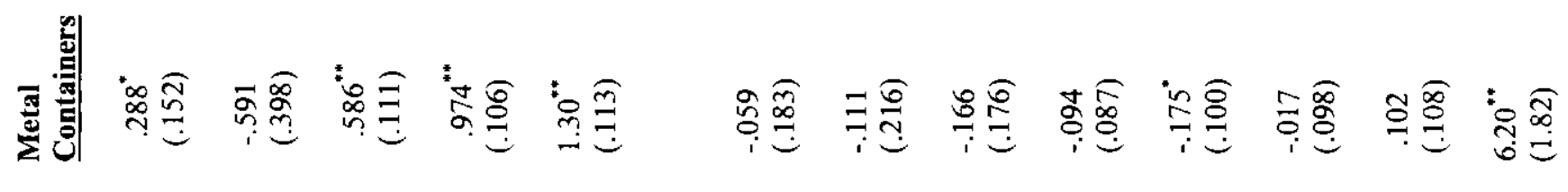

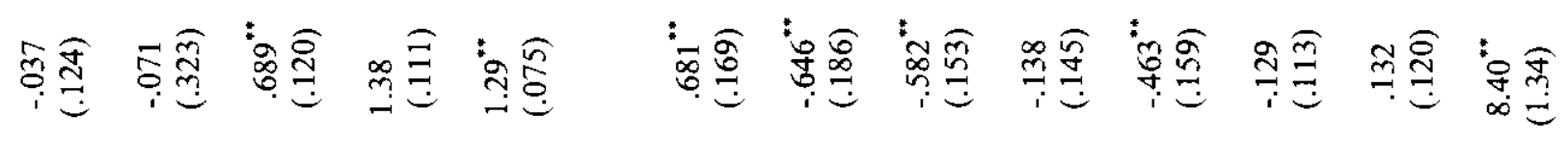

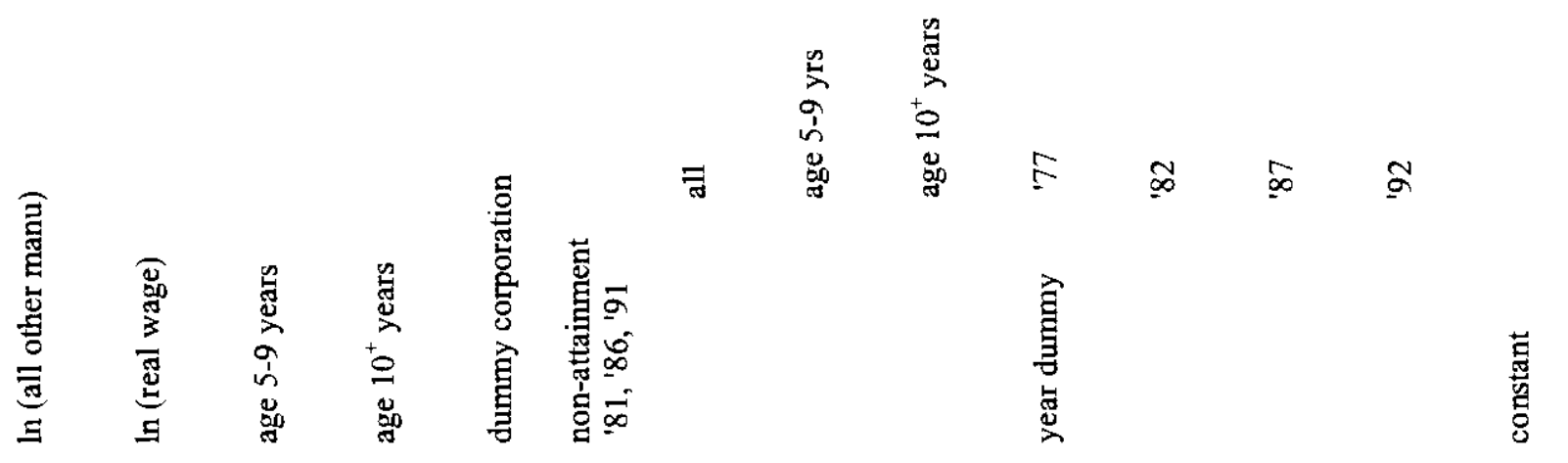




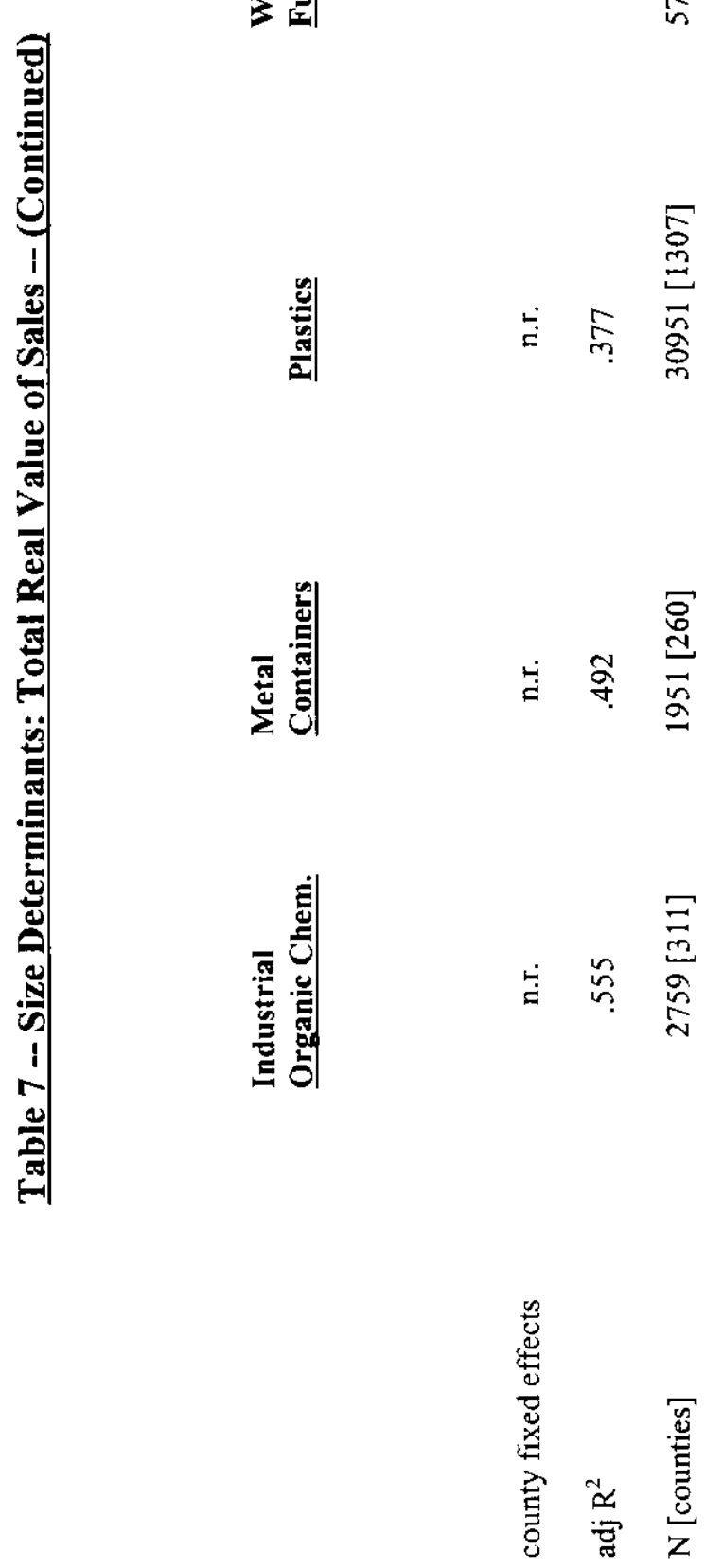


that plants $10+$ years are of similar size in non-attainment counties. For these plants, for industrial organic chemicals, plastics and wood furniture, the net effects of non-attainment status for older plants are $(.68-.58, .22-.25$, and $.45-.53)$. In Table 8 these non-attainment effects are broken out by year. Generally effects of 1981 attainment status on 1982 size are not so important, except for wood furniture. Strong effects exist in 1987 and 1992, where for example for industrial organic chemicals, new plants in non-attainment counties are $95 \%$ larger in sales than their counterparts in attainment counties (controlling for observed and unobserved county characteristics). Again, with age, the differences appear to evaporate. Effects for metal containers also appear in 1987 and 1992, although positive effects for new (all) plants seem to be outweighed by negative effects with aging.

Cohort regressions (with county fixed effects) support the results in Table 8. Cohort regressions apart from county covariates and fixed effects have 42 dummy variables, one for each birth year-Census time (starting in 1972), with a differential dummy for each of those for 1982 and beyond for non-attainment status. For example, for organic chemicals, metal containers, plastics, and wood furniture, for each industry respectively, the triplets of the percents by which average plant sizes for new plants in non-attainment areas exceed those in attainment areas in 1982, 1987, and 1992 are $(41,21,67),(22,-41,-81),(3,21,13)$, and (55, $34,57)$. These patterns are similar to those in Table 8 , and it remains that results for the small sample size metal containers do not correspond to those for the other industries. For new plants in 1982, after 10 years in 1992, the percent differentials in average plants sizes in non-attainment compared to attainment areas are insignificant. Plants in attainment areas catch-up to their non-attainment counterparts with age.

In summary from Tables 7 and 8 and cohort regressions, it appears non-attainment status and its ensuing regulations affect the timing of plant investments. Given the costs and structure of environmental negotiation and perhaps the nature of equipment specifications, rather than traditional phasing-in of investments (practiced in attainment counties), plants in non-attainment counties do larger up-front investments starting off with larger operations. 


\section{Table 8 -- Total Real Sales: Time Varying Non-Attainment Status}

Ind. Org.

Chemicals
Metal

Containers
Plastics

$.091^{\circ}$
$(.051)$

(.269)

.427

$(.314)$

.326

$(.265)$
$-.087$

(.053)

$-.048$

(.046)
Wood

Furniture

1981 non-attain.

all

age $5-9$

age $10^{+}$
-.320
$(.250)$

$-.149$

(.196)
$.404^{* *}$

(.099)

$-.267^{* *}$

(.132)

$-.526^{* *}$

(.108)

1986 non-attain.

all

age 5-9

age $10^{+}$
.814"*

(.227)

$-.860^{* * *}$

(.279)

$-.735^{* *}$

(.221)
.132

(.254)

$-.622^{\circ}$

(.365)

$-.413^{*}$

(.247)
$.401^{* *}$

(.049)

$-.294^{\circ *}$

(.053)

$-.457^{* *}$

(.045)
$-.590^{* *}$

(.118)

$.523^{* *}$

(.105)

$-.255$

(.122)

* 0 **

(.118)

1991 non-attain.

all

age 5-9

age $10^{+}$
.954 *

(.239)

$-.862^{* *}$

(.308)

$-.982^{* *}$

(.277)
.293

(.300)

$-.340$

(.367)

$-.555^{*}$

(.300)
$.196^{* *}$

(.050)

$.438^{\circ *}$

(.116)

$-128^{\circ *}$

(.057)

$-.247^{\circ}$

(.046)

.


With time, plants in attainment counties catch-up. This greater up-front commitment may explain increased survival rates of plants in non-attainment counties following regulation in industrial organic chemicals and plastics in Table 4. Greater required up-front commitment leads to more caution and improved survival.

The final comment on these size estimates concerns the time dummies in Table 7. Other things being equal, plants in 1992 don't seem to be smaller generally than plants in the base year 1972. The only pattern among the time dummy variables is that, in 1982, they are all (significantly) negative. 1982 is not a recession year (1983 was the peak of the business cycle). One interpretation is that 1982 was (for our five year spaced sample) the height of regulatory uncertainty following the key 1977 CAA amendment. Plants, again under Pindyck cost uncertainty, stepped back - didn't expand or renew as would generally occur. That is reflected in temporarily reduced scales of operation, biggest in the most affected industry, chemicals.

The Table 7 formulation doesn't allow specifically for cohort size effects of regulation. While there appear to be no patterns common to all industries, earlier we noted industry specific patterns for industrial organic chemicals. For industrial organic chemicals, cohort regressions support the notion that new plants grow to smaller sizes than pre-regulation plants. In Table 9, we give the percentage for different birth cohorts by which sizes of plants of different ages exceed the base category (sizes of 72 plants in 1972) for all plants (controlling for differential impacts of non-attainment status). With one exception (15 year old 1977 plants) 1967 plants are larger than all subsequent plants, controlling for age in industrial organic chemicals.

\section{Conclusions and Assessment}

The key tool of air quality regulation is stringency of equipment specifications, to limit emissions from production processes. The stringency of regulation has varied over time and space and by plant size, age, and visibility. Officially, stringency varies by space 
Table 9 -- Percent Birth Cohort Size Differentials, Controlling for

\section{Age in Industrial Organic Chemicals}

(cohort regressions, where sizes of ' 72 plants in '72 is the base)

\begin{tabular}{|c|c|c|c|c|c|}
\hline & & 67 & $\underline{72}$ & 77 & $\underline{82}$ \\
\hline age & $5-9$ & $107^{* *}$ & $59^{* *}$ & 43 & 62 \\
\hline & $10-14$ & $126^{* *}$ & 11 & $97^{* *}$ & $97^{*}$ \\
\hline & $14-20$ & $124^{* *}$ & $81^{* *}$ & $145^{* *}$ & n.a. \\
\hline & $20-24$ & $187^{\circ *}$ & $98^{* *}$ & n.a. & n.a. \\
\hline
\end{tabular}


according to non-attainment versus attainment status of counties; it varies by plant size, according to the plant's perceived potential to pollute; and it varies by age, according to whether the plant is new or already in business. Unofficially, stringency varies by time, given slower implementation for smaller plants; and it varies currently by plant size given regulatory strategies to focus inspections and monitoring on bigger plants. An alternative to the current regulatory regime would be complete uniformity of regulation by space, size and age. In this section we review our results and discuss the effects of regulation, using complete uniformity as a benchmark of comparison.

In this paper we find the following:

(1) Births fall dramatically in non-attainment counties, compared to attainment counties, with the advent of regulation, with effects increasing with the extent of non-attainment of air quality standards. The shift in birth patterns induces a reallocation of stocks of plants towards attainment areas. Depending on the interpretation of reduced form coefficients, net present value for a typical new plant in a non-attainment area could fall by $25-45 \%$. Those numbers do seem large, although they are just for these very heavy polluters. The shift in plants has affected air quality (Henderson, 1996). First, the reduction in stocks in non-attainment areas has helped bring those areas into attainment. Second, the shift of key industries (plastics and industrial organic chemicals in Henderson, 1996) to attainment areas causes air quality degradation there. These are unintended consequences of the Clean Air Act, but not necessarily bad ones. Spreading out of pollution, which lowers ozone peaks in low air quality areas, may improve health. Whether that is correct or not is part of the current debate on whether negative health effects are driven by ozone peaks, or spikes, versus prolonged exposure to lower levels of ozone.

How do these outcomes compare to a regulatory policy which was uniform by space? There would be no incentive for plants to relocate to attainment areas. That would improve production efficiency. However, it would not lead to the spreading-out of pollution, which may be good or bad! 
(2) Regulation spurred births in the small scale non-affiliate sector, compared to the corporate sector. However, survival rates of these non-affiliates in the early years of regulation were very poor. Only in metal containers and wood furniture is there a sustained gain in non-affiliate births and stocks, resulting in an increase in their market share of plants. To evaluate the cost of this shift we would need to know the shape of long-run cost functions for these industries, an exercise beyond the scope of this paper. From an environmental point of view, the shift is probably bad. It presumably promotes growth of small, relatively dirty (unregulated) plants. Of course, focusing on big polluters may be a cost-effective regulatory strategy, given the costs of regulation itself.

In the short-run, in the early years of regulation, there was a burst of non-affiliate births with poor survival rates. These could be viewed as experiments made to learn about (a) the market potential for non-affiliates especially in non-traditional attainment areas and (b) the extent to which small plants would escape regulation in non-attainment areas. For example, in industrial organic chemicals, in 1977-82 there were 45 failures to 10 survivors among nonaffiliate births in attainment areas at a $\$ 450,000-\$ 500,000$ investment commitment each. A more typical number of survivals in attainment areas (averaging 1972-77 and 1982-87 numbers) for 55 births would have been 25 .

Obviously uniform regulation by space and plant size would have stopped both such experimentation and the changes in industrial structure in metal containers and wood products. However, if the same regulatory activity budgets were spent more uniformly across big and small polluters, that might lead to worse air quality.

(3) Grandfathering of pre-regulation plants and of new regulation era plants to successive tightening of regulations raises survival rates. That limits "natural" plant turnover, keeping otherwise unprofitable operations in business. It also slows the improvement in air quality, as older, dirtier plants have prolonged lives. A more uniform policy with respect to age would have encouraged retrofitting and other anti-pollution activities of existing VOC and $\mathrm{NO}_{x}$ emitters much earlier on in the regulatory process. 
(4) Investment or growth patterns of plants appear to be affected by regulation. In particular, relative to attainment areas, new plants subject to strong regulation in nonattainment areas start off significantly larger (more up-front investment), but overtime (within 10 years) converge in sizes to plants in attainment areas (with more phased-in investments). This difference across space in growth patterns probably means investments in non-attainment areas are more cautious (since they involve bigger sunk investments), limiting turnover in those areas, while attainment areas attract more risky investments. Again, these are spatial distortions. 


\section{References}

Andersen, E. B. (1972), "The Numerical Solution of a Set of Conditional Estimation Equations," Journal of the Royal Statistical Society, Series B, 34, 42-54.

Bartelsman, Eric and Wayne Gray. NBER Manufacturing Productivity Database. Available at: http:/nber.harvard.edu/pub/productivity.

Bartik, Timothy J. (1988), "The Effects of Environmental Regulation on Business Location in the United States," Growth and Change. 19(3), 22-44.

Dixit, A. and R. Pindyck (1994), Investment Under Uncertainty, Princeton University Press. Environmental Protection Agency (1971), "Requirements for Preparation, Adoption, and Submittal of Implementation Plans," Federal Register, August 14.

Environmental Protection Agency (1972), Federal Air Quality Control Regions, Rockville, MD: EPA Office of Air Programs.

Environmental Protection Agency (1973), The National Air Monitoring Program: Air Quality and Emission Trends (Annual Report). Research Triangle Park, NC: EPA Office of Air Quality Planning and Standards.

Environmental Protection Agency (1978a), Air Quality Criteria for Ozone and Other Photochemical Oxidants, Research Triangle Park, NC: EPA Environmental Criteria and Assessment Office.

Environmental Protection Agency (1978b), Summary of Group I Control Technique Guideline Documents for Control of Volatile Organic Emissions from Existing Stationary Sources, Research Triangle Park, NC: EPA Office of Air Quality Planning and Standards.

Environmental Protection Agency (1992a), National Air Pollutant Emission Estimates, 1900-1991. Research Triangle Park, NC: EPA Office of Air Quality Planning and Standards.

Environmental Protection Agency (1992b), National Air Quality and Emission Trends Report. Research Triangle Park, NC: EPA Office of Air Quality Planning and Standards. 
Environmental Protection Agency (1995), Sector Notebook Project. Various volumes), Washington, DC: EPA Office of Compliance.

Gray, Wayne B. (1996), "Does State Environmental Regulation Affect Plant Location?" Clark University mimeo.

Hausman, Jerry and Bronwyn H. Hall, and Zvi Griliches (1984), "Econometric Models for Count Data with an Application to the Patents - R \& D Relationship," Econometrica, 52(4), 909-938.

Henderson, J.V. (1994), "Where Does an Industry Locate," Journal of Urban Economics, 35, 83-104.

Henderson, J. Vernon (1996), "Effects of Air Quality Regulation," American Economic Review, 86(4), 789-813.

Henderson, J. Vernon, Ari Kuncoro, and Matthew Turner (1995), "Industrial Development in Cities," Journal of Political Economy, 103, 1067-1090.

Jovanovic, B. (1982), "Evolution and the Selection of Industries," Econometrica, 649-670.

Kahn, Matthew E. (1994), "Regulation's Impact on County Pollution and Manufacturing Growth in the 1980's," Columbia University mimeo.

Laws, Elliot P. (1992), "The Regulation of Stationary Sources," in Timothy A. Vanderver, Jr., ed., Clean Air Law and Regulation, Washington, DC: The Bureau of National Affairs.

Levinson, Arik (1994), "Environmental Regulation and Manufacturers' Location Choices: Evidence from the Census of Manufactures," University of Wisconsin mimeo.

Liroff, Richard A. (1986), Reforming Air Pollution Regulation. Washington, DC: The Conservation Foundation.

McConnell, Virginia D. and Robert M. Schwab (1990), "The Impact of Environmental Regulation on Industry Location Decisions: The Motor Vehicle Industry," Land Economics, $66(1), 67-81$.

Melnick, R. Shep, (1983), Regulation and the Courts: The Case of the Clean Air Act. Wash- 
ington, DC: The Brookings Institute.

Papke, Leslie E. (1991), "Interstate Business Tax Differentials and New Firm Location: Evidence from Panel Data," Journal of Public Economics, 45, 47-68.

Pindyck, Robert S. (1993), "Investments of Uncertain Cost," Journal of Financial Economics, 34, 53-76.

Waxman, Henry A. (1992), "The Clean Air Act of 1990: An Overview of Its History and Policy," in Timothy A. Vanderver, Jr., ed., Clean Air Law and Regulation, Washington, DC: The Bureau of National Affairs.

Wooldridge, Jeffrey M. (1991), "Specification Testing and Quasi-Maximum Likelihood Estimation," Journal of Econometrics, 48, 29-55. 
All Births

(1)

(2)

$\begin{array}{lc}\ln (\text { manu. employ.) } & .463 \\ & (.142) \\ \ln \text { (real wage) } & -.834^{\circ} \\ & (.466) \\ \text { non-attainment } & -.450^{* *} \\ (78,82,87) & (.132)\end{array}$

non-attainment

1972 for $72-77$ births

non-attainment

1978 for $77-82$ births

non-attainment

1982 for $82-87$ births

non-attainment

1987 for $87-92$ births

Period 1963-67

Period 1972-77

Period 1977-82

Period 1982-87

Period 1987-92

$\mathrm{T}$

$\mathrm{N}$

Pseudo R ${ }^{2}$

Robust Hausman statistic

$-.450^{* *}$

(.132)

-.223
$(.138)$

(.217)

$.551^{* *}$

(.142)

(.141)

(.185)

6

16.77

$$
\begin{aligned}
& .466^{* *} \\
& (.141)
\end{aligned}
$$

$-.854^{*}$

(.469)

.097

(.192)

-.456 "

(.192)

$-.616^{* *}$

(.187)

. .279

(.192)

$-.226$

(.138)

.105

(.258)

$.555^{* *}$

(.182)

$.369^{* *} \quad .483^{* *}$

(.167)

$\begin{array}{ll}.437^{* *} & .334^{*} \\ (185) & (.199)\end{array}$

(.199)

6

415

.615

21.01
11.71

$\underline{\text { Non-Affiliate Births }}$

(3)

(4)

$.424^{* *}$

(.214)

$.468^{* *}$

(.195)

.306

(.736)

$-1.52 "$

(.644)

$-.487^{*}$

(.271)

$.566^{* *}$

(.268)

$-.292$

$-.532^{* *}$

(.251)

$-.603^{* *}$

(.247)

-.647
$(.286)$

$-.250$

(.251)

(.296)

.110

(.207)

$-.454^{* *}$

(.176)

.104

$-.021$

(.375)

.095

(.301)

$.783^{* *}$

(.241)

$.599^{* *}$

(.257)

$.389^{\circ}$

(.222)

.095

(.318)

$.469^{*}$

(.268)

6

6

212

316

.450

.453

16.46

- Significant at $10 \%$ level

** Significant at $5 \%$ level 


\section{All Births}

(1)

(2)

Corporate Births

(3)

$\begin{array}{cc}.576^{* *} & .145 \\ (.237) & (.223) \\ & \\ 1.05 & .227 \\ (1.08) & (.873)\end{array}$

non-attainment

$(78,82,87)$

non-attainment

1972 for $72-77$ births

non-attainment

1978 for $77-82$ births

non-attainment

1982 for $82-87$ births

non-attainment

1987 for $87-92$ births

Period 1963-67

$\begin{array}{ll}-.387^{* *} & -.389^{* *}\end{array}$

(.147)

(.147)

Period 1972-77

$-.216^{*}$

$-.136$

(.122)

(.167)

Period 1977-82

$-.035$

$-.067$

(.196)

(.260)

Period 1982-87

$-.051$

(.170)

$-.074$

(.220)

Period 1987-92

$$
-.247
$$

(.167)

$-.183$

(.179)

$\mathrm{T}$

$\mathrm{N}$

Pseudo $\mathrm{R}^{2}$

Robust Hausman

statistic

* Significant at $10 \%$ level

* Significant at 5\% level

\section{$6 \quad 6$}

$334 \quad 334$

.534

8.05
$-.159$

(.261)

$-.658^{*}$

(.371)

.142

(.377)

$-.135$

(.344)

$-.115$

(.183)

$-.316$

(.231)

$-.148$

(.342)

$-.799^{* *}$

(.344)

$-.881^{* *}$

(.271)

6

215

.352

6.41

\section{$\underline{\text { Non-Affiliate Births }}$}

(4)

.145

.227

(.873)

$-.092$

(.281)

.051

(.422)

$-.590^{*}$

(.316)

$-.683^{* *}$

(.291)

$-.730^{* *}$

(.236)

.054

(.259)

.132

(.407)

$.647^{* *}$ (.289)

$.512^{* *}$

(.259)

6

212

.446

9.41 


\section{All Births}

(1)

(2)

Corporate Births

(3)

$.337^{* *}$

(.076)

.069

$(.277)$
Non-Affiliate Births

(4)

$416^{* *}$

(.063)

.245

(.206)

$\begin{array}{ll}\text { non-attainment } & -.261^{* *} \\ (78,82,87) & (.047)\end{array}$

non-attainment

$.104^{* *}$

1972 for $72-77$ births

(.039)

$-.034$

(.083)

$.142^{* *}$

(.044)

non-attainment

$-.023$

(.049)

$-.366^{* *}$

(.100)

.050

(.057)

non-attainment

$-.245^{* *}$

(.057)

$-.414^{* *}$

(.097)

$-.184^{* *}$

(.062)

$-.367^{* *}$

(.065)

$-.453^{* *}$

(.098)

$-.351^{* *}$

(.068)

Period 1963-67

$-.591^{* *} \quad-.592^{* *}$

$-.457^{* *}$

(.082)

$-.626^{* *}$

(.073)

Period 1972-77

$\begin{array}{ll}.099 & .033\end{array}$

$(.063) \quad(.072)$

.131

(.116)

$-.066$

(.076)

Period 1977-82

$.253^{* *}$

.062

(.061)

.123

(.109)

.040

(.068)

Period 1982-87

$.170^{* *} \quad .158^{* *}$

$(.067) \quad(.075)$

.074

$.385^{* *}$

(.121)

(.080)

Period 1987-92

$.165^{*} \quad .232^{* *}$

$.244^{*}$

$.218^{\circ *}$

(.146)

(.097)

$\mathrm{T}$

6

6

6

6

$1575 \quad 1575$

1001

1443

$.931 \quad .937$

.810

.936

$15.35 \quad 16.54$

12.71

17.46

Robust Hausman statistic

* Significant at $10 \%$ level

${ }^{*}$ Significant at $5 \%$ level 
(1)

$\ln$ (real wage)

non-attainment

$(78,82,87)$

non-attainment

1972 for $72-77$ births

non-attainment

1978 for $77-82$ births

non-attainment

1982 for $82-87$ births

non-attainment

1987 for $87-92$ births

Period 1963-67

Period 1972-77

Period 1977-82

Period 1982-87

Period 1987-92

$\mathrm{T}$

$\mathrm{N}$

Pseudo R ${ }^{2}$

Robust Hausman statistic
All Births

(2)

$$
\begin{aligned}
& .177^{* *} \\
& (.060)
\end{aligned}
$$

Corporate Births

(3)

$\begin{array}{lc}-.071 & .184^{* *} \\ (.216) & (.061) \\ & \\ -.649 & .033 \\ (.822) & (.228)\end{array}$

(.225)

$-.012$

(.225)

$-.289^{* *}$

(.065)
.027

(.278)

.050

(.311)

$-.547^{\circ}$

(.299)

$-.520^{*}$

(.307)

$-.846$

(.194)

$-.184$

(.224)

$-.542^{*}$

(.299)

.040

(.267)

$-.280$

(.297)

6

255

.423

10.41 $\underline{\text { Non-Affiliate Births }}$

(4)

$.184^{* *}$

.033

(.228)

.023

(.071)

$-.111$

(.089)

$-.267^{* *}$

(.090)

$-.445^{* *}$

(.085)

$-.094^{* *}$

(.046)

$.328^{\circ *}$

(.071)

.105

(.090)

$.323^{\circ *}$

(.081)

$.210^{* *}$

(.089)

6

1185

.924

16.59

- Significant at $10 \%$ level

** Significant at $5 \%$ level 


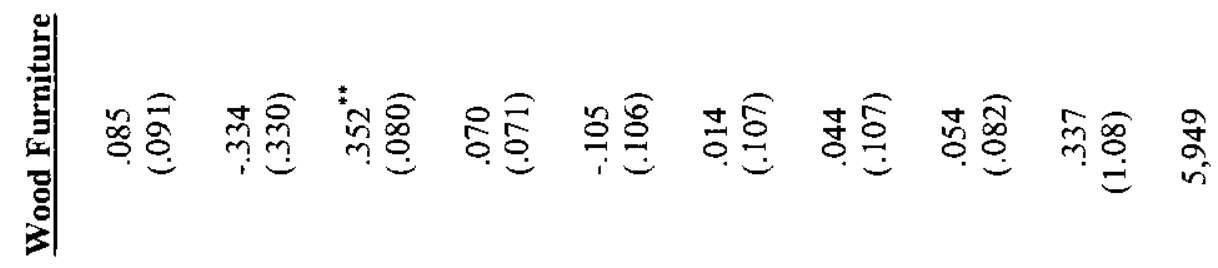

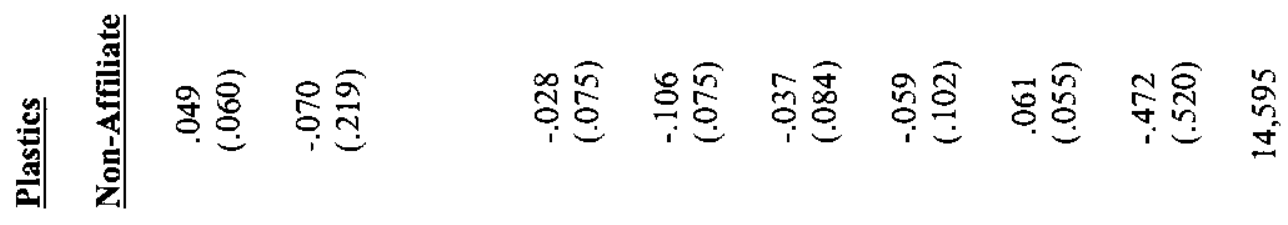

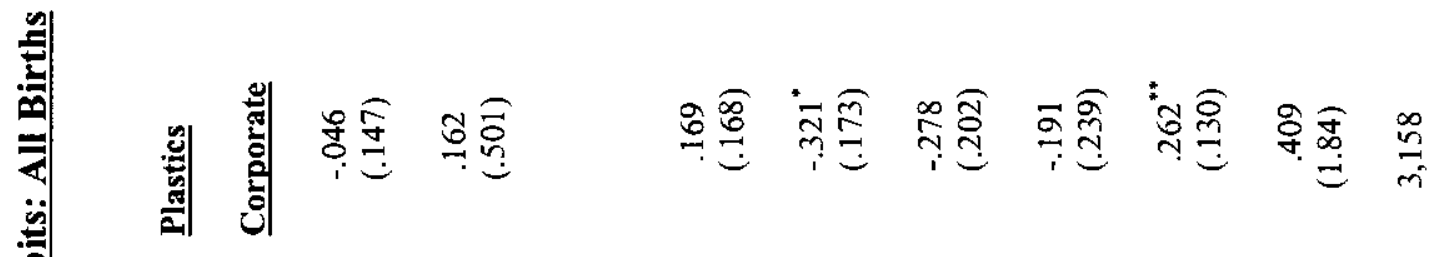

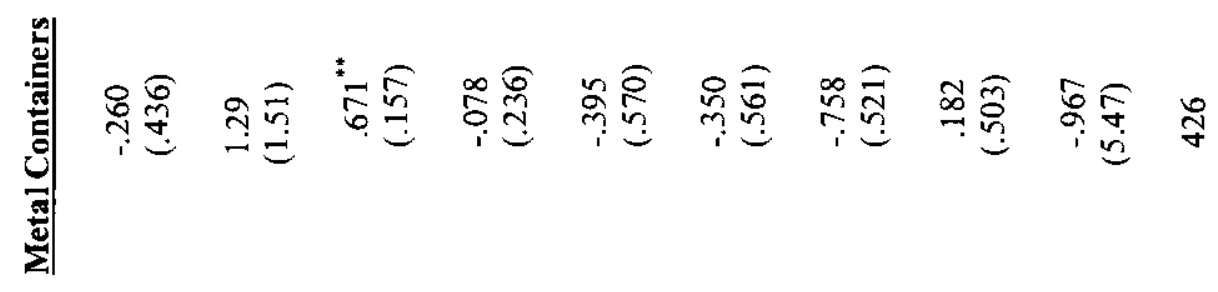

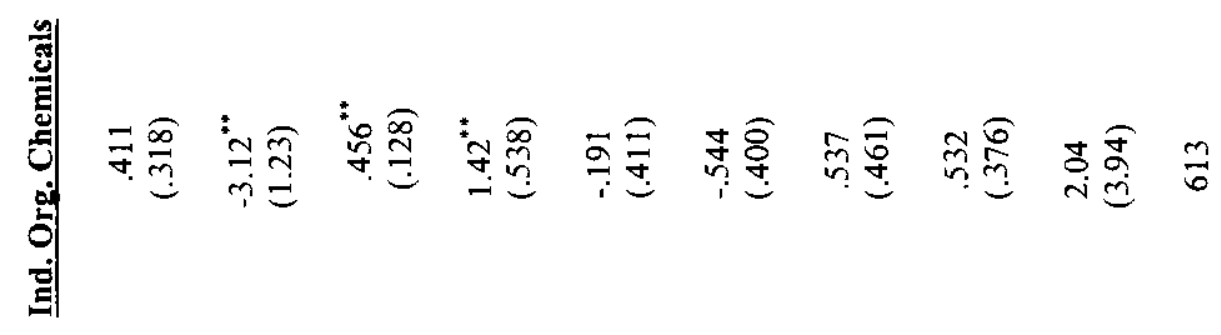

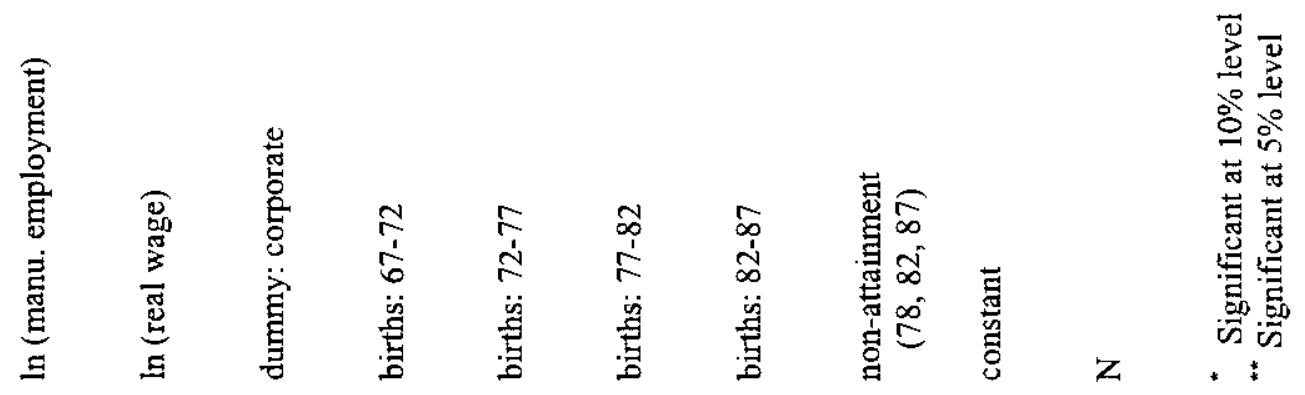


Table A6 -- Survival Probits: Attainment Status Effects By Year

\section{Plastics}

Ind. Org.

Chemicals

$$
\begin{array}{r}
\text { non-attainment } 72 \\
\text { (survival to } 77 \text { ) } \\
\text { non-attainment } 77 \\
\text { (survival to } 82 \text { ) } \\
\text { non-attainment } 82 \\
\text { (survival to } 87 \text { ) } \\
\text { non-attainment } 87 \\
\text { (survival to 92) }
\end{array}
$$

$$
\begin{gathered}
-.713 \\
(.547) \\
1.81^{*} \\
(1.02) \\
.446 \\
(.645) \\
.278 \\
(.434)
\end{gathered}
$$

births $67-72$

$2.05^{\circ *}$

(.715)

births $72-77$

births $77-82$

births $82-87$
$-1.43$

(1.01)

-.476
$(.635)$

.737

(.493)

\section{Corporate}

.0018

(.143)

$.465^{* *}$

(.199)

$.678^{* \circ}$

$(.197)$

.013

(.155)
Non-

Affiliates

$.119^{\circ}$ (.063)

$.258^{* *}$

(.090)

$.149^{\circ}$

(.078)

$-.022$

(.069)

$-.112$

(.086)

(.192)

$-.282^{\circ}$

(.098)

-.510
$(.217)$

$-.109$

(.097)

(.238)

.0034

(.105)

* Significant at $10 \%$ level

- Significant at 5\% level 